\title{
Characterisation and Environmental Value Proposition of Reuse Models for Fast-Moving Consumer Goods: Reusable Packaging and Products
}

\author{
Żaneta Muranko * (D), Catriona Tassell (1), Anouk Zeeuw van der Laan (D) and Marco Aurisicchio (D) \\ Dyson School of Design Engineering, Imperial College London, London SW7 2DB, UK; \\ c.tassell19@imperial.ac.uk (C.T.); a.zeeuw-van-der-laan16@imperial.ac.uk (A.Z.); \\ m.aurisicchio@imperial.ac.uk (M.A.) \\ * Correspondence: z.muranko@imperial.ac.uk
}

check for

updates

Citation: Muranko, Ż.; Tassell, C.; Zeeuw van der Laan, A.; Aurisicchio, M. Characterisation and Environmental Value Proposition of Reuse Models for Fast-Moving Consumer Goods: Reusable Packaging and Products. Sustainability 2021, 13, 2609. https:// doi.org/10.3390/su13052609

Academic Editor: Gordon

L. Robertson

Received: 11 November 2020

Accepted: 5 February 2021

Published: 1 March 2021

Publisher's Note: MDPI stays neutral with regard to jurisdictional claims in published maps and institutional affiliations.

Copyright: (c) 2021 by the authors. Licensee MDPI, Basel, Switzerland. This article is an open access article distributed under the terms and conditions of the Creative Commons Attribution (CC BY) license (https:// creativecommons.org/licenses/by/ $4.0 /)$.
Abstract: Problem: Fast-Moving Consumer Goods (FMCGs) are products that are purchased and consumed frequently to satisfy continuous consumer demand. In a linear economy, FMCGs are typically offered as single-use and disposable products. Limitations in product design, insufficient collection systems, and inefficient recovery processes prevent high recycling rates. As a result, FMCGs often end up in landfill or the environment, contributing to waste accumulation, and pollution. Whilst recycling is the most common waste prevention strategy practiced by the industry, the process is limited to addressing only the final stage of the product life cycle, omitting the overproduction and consumption of materials typical of FMCGs. Instead, reuse is a strategy that is capable of extending the value of resources by slowing material flows. Novel reuse models that require the consumer to interact with durable primary packaging and products are emerging in the FMCG industry. However, the constituent elements and operation principles of such reuse models are not fully understood. The aim of this research is to develop a comprehensive characterisation of reuse models and to evaluate their potential to deliver environmental value. Method: Ninety-two reuse offerings were selected and analysed to identify their reuse system elements. The analysis led to the identification of a framework including five reuse models, which were also evaluated to establish their capability to deliver environmental value when compared to conventional single-use and disposable FMCGs. Results: Currently in the FMCG sector, reusable products are mostly durable packaging, such as bottles and containers for beverages, foods, personal and home care goods, and are infrequently durable products, such as personal and baby care goods, including razors and nappies. Three reuse models involve exclusive reuse, a behaviour by which a reusable product is used and kept by a single user throughout the product lifetime. In exclusive reuse models, users are provided with either a reusable product (model 1), a reusable product with preparation for reuse infrastructure (model 2), or access to preparation for reuse infrastructure (model 3). Two reuse models involve sequential reuse, a behaviour by which a reusable product is used by multiple users throughout the product lifetime and returned after each use to a provider. In sequential reuse models, users are provided with either a reusable product with preparation for reuse infrastructure and provider-operated recovery services (model 4), or a reusable product and provider-operated services for recovery and preparation for reuse (model 5). Whilst the five reuse models can operate standalone, some offerings were found to embed a multi-model approach. Both exclusive and sequential reuse models are capable of delivering environmental value by reducing the use of natural resources and retaining their value in the economy. In particular, sequential reuse models were found to have a greater capability to increase the share of recyclable resources by offering access to infrastructure for the closure of material loops. Conclusions: Consumers can currently access five reuse models and choose between exclusive and sequential reuse behaviours. When adopted in conjunction with recycling, reuse models can enable a more efficient consumption of FMCGs. Providing the infrastructure necessary to enable reuse and recycling is key to the successful and sustainable deployment of the reuse models.

Keywords: reuse; consumer behaviour; reuse models; reusable products; reusable packaging; refillable packaging; returnable packaging; fast-moving consumer goods; circular economy 


\section{Introduction}

Fast-Moving Consumer Goods (FMCGs) are mass-produced products that conveniently and recurrently meet consumers demand [1]. The production, distribution, and delivery of FMCGs to a global market requires a continuous supply of materials and energy [2]. FMCGs have short lifespans as they are typically designed for single-use and disposal $[1,3]$. Once they reach the end of life, some FMCGs enter the waste stream to recover materials. However, due to inefficiencies in collection and recovery systems, driven by adverse consumer behaviour, underdeveloped infrastructure, and lack of recyclability by design, FMCGs often are diverted to landfill and incineration, contributing to waste accumulation and pollution to air, water, and soil [4]. Therefore, FMCGs operate in a linear economy system, whereby products are manufactured using virgin resources that are mass consumed and disposed of at the end of life.

Instead, in a circular economy, FMCGs are designed using strategies that keep a high utility of resources, are manufactured using sustainable materials, and at the end of their functional life re-enter the economy either as recycled materials or reusable packaging and products.

Recycling is a critical process that can retain the flows of materials within the economy. For FMCGs, specifically packaging, the process typically follows five key stages: (1) consumer disposal, (2) collection, (3) sorting, (4) reprocessing, and (5) production of recycled materials [5]. As a waste management strategy, recycling needs to be pursued further by the FMCGs industry to ensure that not only packaging materials are recovered but also other types of end-of-life products, e.g., razors and nappies [4]. In particular, there is a need to improve both the design of packaging and products for recyclability and the design of systems for collection and recovery [6]. In conjunction with these improvements, it is also important for the industry to find means to encourage consumer recycling behaviour and ensure that products are disposed of into the correct waste streams once they have reached the end of their useful life [7]. Nonetheless, recycling is an energy-intensive process and outcomes, i.e., the recovered materials and their value, are affected by the contamination and loss of physical properties [8]. This makes it less desired than other waste management strategies, such as reuse. In addition, recycling leaves the important question of how to slow down the wasteful use of materials due to the frequency and scale of FMCG use unanswered [9].

Reuse is a waste management strategy which involves operations that can slow the flows of materials specifically by extending the product utility [10]. For FMCGs, specifically packaging, the process of reuse involves an operation by which products or components are used again for the same purpose for which they were conceived, with or without the support of auxiliary products present on the market [11,12]. Very little reuse occurs today in the FMCG sector partly due to the "one-off" nature of consumption [4]. However, recently circular FMCG offerings have emerged that adopt novel reuse models and redefine the look of products, primary packaging, operations, and ecosystems. For example, new types of reusable packaging can be refilled by the bulk dispenser or parent packaging and are returnable [10]. The development of these reuse models requires a comprehensive understanding of their constituent elements. However, current literature on reuse is limited and does not provide a systematic overview of how reuse models are designed and what environmental value proposition they offer. This understanding is important to support the transition of the FMCG sector towards reuse.

The aim of this research is to investigate reuse models implemented by the FMCG industry to (1) understand the differences between their constituent reuse system elements and (2) evaluate their environmental value proposition. In line with the EU Waste Framework Directive, reuse is defined as "any operation by which products or components [ ... ] are used again for the same purpose for which they were conceived" (Directive 2008/98/EC; Article 3.13, p. 312/10 [12]). The definition of reuse adopted in this research concerns the recurring utilisation of "unmodified" products. As such, it does not address reuse operations that involve repurposing, refurbishment, or remanufacture, which are 
considered in other definitions of reuse (e.g., Ecodesign Directive 2009/125/EC [13]). “Traditional" single-use and disposable FMCGs comprise packaged fluids (e.g., beverages and gases), soft solids (e.g., foods and cosmetics), and solid (e.g., razors, toothbrushes and menstrual cups) products. In reuse models, FMCGs become durable in terms of both packaging and/or products. In this paper, the term reusable product is used to refer to either durable packaging or durable products. More so, the terms reusable packaging and reusable vessel (including both bottles and containers) are used to refer to durable primary packaging.

The paper is organised into the following sections. Section 2 reviews the literature on reuse behaviour, reuse frameworks, and the environmental value of reuse models. Section 3 outlines the research methodology. Section 4 presents the identified reuse models. Section 5 evaluates how the reuse models deliver environmental value. Section 6 provides a discussion of results before concluding the study in Section 7 .

\section{Background}

\subsection{Reuse of FMCGs}

In the EU Waste Framework Directive (Directive 2008/98/EC [12]), reuse occupies a prominent position, which is featured in second place after reduce-the most efficient strategy. Reuse is followed by recycling - a practice that is becoming a normative disposal habit [14]. In the FMCG industry, reuse has mainly received attention from a primary packaging perspective. The BS and ISO standards and EU directives provide definitions of reuse, as presented in Table 1. These definitions bring out a systemic and performancecentred view on reuse, as they refer to the existence of a reuse system, auxiliary products to support reuse, a minimum number of reuse rotations or trippage [15], and the fact that eventually, reusable packaging becomes waste and requires recycling. Although it is not explicitly included in the definitions, the standards and directives also define the operations needed to enable reuse. For example, ISO 18603 [16] reports that reconditioning for reuse includes operations such as assessment of packaging condition, removal and replacement of damaged or non-reusable components, cleaning or washing according to relevant conditions, inspection, and assessment of fitness-for-purpose.

Whilst reuse is currently an emerging practice, it is not new to the consumer. For example, archaeological findings related to the Bronze Age have evidenced repair activities being performed on broken or discarded pottery to enable the reuse of ceramics in Greece [17] and the reconditioning of razors made from bronze and iron for reuse across Europe [18]. Records of public actions in late 18th century European countries, e.g., the Netherlands, show that various second-hand household products, such as kitchen utensils, were commonly bought for reuse [19]. During the same period, in the UK, reuse was also practiced for products such as durable bottles that were lent to a consumer and returned to the lender upon their goodwill and with the support of financial incentives, e.g., milk bottles [20]. The milkman model continued as a widespread practice of bottle reuse until very recently, with $74 \%$ of UK households still using this doorstep delivery and return service in 1989 [21]. Unlike many contemporary FMCGs, those products were made for longevity and therefore intended for repair and reuse. Despite the evidence of reuse practices in past history, following World War II, a steep rise in "throwaway" culture can be observed that is particularly synonymous with the FMCG industry [22]. 
Table 1. Definitions of reuse and reusable packaging in standards and directives.

\begin{tabular}{ll}
\hline Standards and Directives & Definitions \\
\hline & $\begin{array}{l}\text { Reuse: operation by which packaging, which has been conceived and designed to } \\
\text { accomplish within its life cycle a minimum number of trips or rotations, is refilled } \\
\text { or used for the same purpose for which it was conceived, with or without the } \\
\text { support of auxiliary products present on the market enabling the packaging to be } \\
\text { refilled: such reused packaging will become packaging waste when no longer } \\
\text { subject to reuse } \\
\text { Reusable packaging: packaging or packaging component that has been conceived } \\
\text { Packaging reuse [1] } \\
\text { and designed to accomplish within its life cycle a minimum number of trips or } \\
\text { rotations in a system for reuse }\end{array}$ \\
\hline
\end{tabular}

Directive 2008/98/EC

of the European Parliament and of the Council of 19 November 2008 on waste and repealing certain directives [12]

Directive 2009/125/EC

of the European Parliament and of the Council of 21 October 2009 Establishing a framework for the setting of ecodesign requirements for energy-related products [13]

ISO 18603: 2013

Packaging and the environment-Reuse [16]

BS 8001: 2017

Framework for implementing the principles of the CE in organisations [23]
Reuse: any operation by which products or components that are not waste are used again for the same purpose for which they were conceived

Reuse: any operation by which a product or its components, having reached the end of their first use, are used for the same purpose for which they were conceived, including the continued use of a product that is returned to a collection point, distributor, recycler, or manufacturer, as well as the reuse of a product following refurbishment

Reuse: operation by which packaging is refilled or used for the same purpose for which it was conceived, with or without the support of auxiliary products present on the market enabling the packaging to be refilled

Reusable packaging: packaging or packaging component that has been designed to accomplish or proves its ability to accomplish a minimum number of trips or rotations in a system for reuse

Reuse: operation by which a product, component, or material can be used again without requiring any reprocessing or treatment

\subsection{Reuse Frameworks}

With growing interest in reuse, frameworks of reuse models have progressively emerged in the literature. In 2009, Lofthouse et al. [24] proposed a framework that specifies eight types of refill models, namely lightweight self-contained refill delivered through dispenser, self-dispense, original packaging swapped for new product, deposit system, top-up card, dispensed concentrate, dispensed product, and concentrate mixed in original packaging. The naming of the models is descriptive of both behavioural aspects (such as refilling and self-dispensing) and system elements (such as product, packaging, and dispensing unit). However, the relations and differences between the eight refill models only partly emerge. For example, the fact that the casings of an ink toner and a single-use camera are viewed as refillable packaging indicate that this work takes a refill- and packaging-centric view on the reuse of FMCGs.

In 2019, the Ellen MacArthur Foundation (EMF) [25] proposed four reuse models, namely refill at home, refill on the go, return from home, and return on the go. Based on the study of sixty-nine reuse business-to-consumer offerings (mostly reusable packaging), the EMF framework distinguishes reuse models between two main dimensions, namely the behaviour that consumers are expected to perform, i.e., either refill or return, and the location where the behaviour occurs, i.e., either at home or on the go. Considering the first dimension (i.e., the behaviour to be performed by consumers), it is worth noting that refill and return behaviours are not polar opposites. In fact, the opposite of returning a reusable product is to keep it [1]. Zeeuw van der Laan et al. [1] make the distinction between offerings where the consumer has to keep and take care of their reusable product and offerings where they have to return products for someone else to take care of them on their behalf-a behaviour that is similar to recycling. Moreover, as in Lofthouse et al. [24], the EMF framework [25] takes refill as the descriptor of reuse behaviour. Whilst this term fits 
well with some types of reuse offerings, it does not always provide an accurate description of reuse behaviour as for reusable products that are not refillable packaging. Shifting towards alternative terminology has the potential to increase the generality of the reuse models. Considering the second dimension (i.e., the location within which the behaviour occurs), it can be seen that it is useful to indicate the level of effort required by the consumer to participate in an offering. Overall, the EMF framework is a step forward in bringing out new understanding of reuse offerings, but it primarily frames reuse around specific actions such as refill and return, leaving unaddressed issues such as the ownership of reusable products and the interactions that users have with infrastructure. Notably, reuse models were defined by the use of consumer behaviours, such as refill and on-the-go or at-home locations also in the studies on reusable packaging by Mansour et al. [26] and Long et al. [27].

In 2020, Tassell et al. [28] proposed a framework describing five reuse models developed based on key reuse-enabling behaviours of the consumer and provider, namely consumer replenishes/reconditions, consumer replenishes at home via service, consumer replenishes on the go via service, consumer brings and company replenishes/reconditions via service, and company replenishes for consumer via service. The first three reuse models involve the consumer keeping and replenishing or reconditioning a reusable product, while the last two involve the consumer bringing (referred to as return in EMF framework [25]) and disposing of reusable products. Whilst Tassell et al. [28] continue to use both the behaviour and location as descriptive dimensions of reuse models, their work adds another modelling dimension by specifying the role of the stakeholder (i.e., consumer or provider). This helps differentiate who performs core behaviours such as preparation for reuse (replenishing) and recovery for reuse (reconditioning).

In conclusion, current efforts to characterise reuse models have either contributed a detailed framework of difficult-to-relate models [24] or simplified frameworks that have considered limited dimensions of reuse $[25,28]$. In particular, the behaviours used in the EMF framework to convey the essence of reuse are specific actions such as refill and return, which do not provide a comprehensive understanding. To advance the field, there is a need to develop a new understanding of reuse that brings together the core reuse behaviours, the consumption of the reusable products, and the reuse-enabling infrastructure.

\subsection{Reuse Behaviour and FMCGs}

As an important enabler of the circular economy, consumer behaviour is receiving increasing attention in the literature. Recent studies on the reuse of FMCGs have investigated psychological determinants of consumer behaviour, including perceptions, motivation, perceived behavioural control, attitudes, and cultural backgrounds. In a study on consumer perception towards refillable packaging, Lofthouse et al. [29] identified a set of perceived positive and negative attributes of refill systems (e.g., perceived ease or difficulty of use, clean or messy experience, good or bad product quality and hassle of maintenance). In their study, the perceived attributes are translated into design guidelines to successfully implement reuse and refill models. A study by Choate et al. [30] investigated the factors influencing behavioural intentions towards refilling reusable water bottles instead of purchasing disposable water bottles. Choate et al. [30] suggest that by improving the ability to perform a behaviour, namely through increasing the availability of water refill stations, the consumer can positively shift their behavioural intentions towards reuse. Another study by Ertz et al. [31] found that the consumer's attitudes, subjective norms, perceived behavioural control, and motivation have a significant impact on their intention to use reusable containers. In the same study, Ertz et al. [31] also found that cultural differences have a role in determining reuse behaviours between Asian and Western consumers. For Western consumers, reuse attitudes have a stronger influence on reuse intentions, whereas for Asian consumers, their reuse intentions are influenced by motivation. In a study by Vaughan et al. [32], investigating the behavioural determinants of milk bottle reuse, the consumer's intrinsic sense of care for their local community of milk bottle co-users 
was found to have an important role in driving reuse behaviour and product stewardship. Vaughan et al. [32] describe the observed consumer-to-consumer and consumer-to-business relationships as a network of interdependency.

Other studies on the reuse of FMCGs have investigated the influence of behaviour change interventions, including business-to-consumer communication and financial incentives. In a study on the influence of communication, Bashir et al. [33] administered tailored messages emphasising the environmental benefits and safety of a refill-based home cleaning service, which positively influenced the behavioural intention of consumers to use this type of offering in the future. In addition, Miller et al. [34] found that tailored messages emphasising the environmental value of using durable diapers can influence consumers' behavioural intention to reuse. Similar communication-based interventions were investigated by Poortinga et al. [35] in a study on the consumption of reusable coffee cups, where tailored messages emphasising environmental benefits positively influenced consumer behaviour, resulting in an increased adoption of reuse. Poortinga et al. [35] also investigated the influence of financial incentives and identified that an added monetary charge on disposable coffee cups can increase the use of reusable coffee cups, whereas a discount on the use of reusable cups was ineffective to initiate behaviour change.

\subsection{Environmental Value of Reuse}

As a circular economy strategy, reuse has the potential to reduce environmental impacts, such as waste accumulation and pollution to air, water, and soil, which is caused by the intensive mining, manufacture, distribution, consumption, and disposal of FMCGs.

Novel market propositions, such as business-to-consumer offerings that foster efficient and sustainable consumption of resources, can be assessed on the basis of their potential to deliver environmental value. This assessment can be conducted at various stages of the development (e.g., early stage or late stage) of an offering. In the early stages, the environmental assessment has to be agile and "light", and it typically involves the use of qualitative assessment methods. For example, Rosa et al. [36] present an expert-based qualitative assessment of the environmental benefits of circular business models, including product-oriented service systems, use-oriented service systems, and result-oriented service systems. In addition, Manninen et al. [37] propose a framework for qualitative evaluation of the environmental value proposition of circular business models in which individual offerings are assessed against selected areas of impact by both experts and the authors.

In the late stages, the environmental impacts of an offering are typically assessed through quantitative methods, e.g., Life Cycle Assessment (LCA). LCA studies on the impacts of reusable products compared to single-use and disposable products are receiving increasing attention in the literature. For example, in an LCA study on beverage cups, Changwichan et al. [38] found that multi-use stainless steel cups used for more than 140 times have less adverse environmental impact than single-use take-away cups. A study by Hoffmann et al. [39] showed that cloth diapers have a better environmental performance than disposable diapers, and they can be further improved by optimised reuse enabling services. Another study by Hait et al. [40] on non-packaging products established that reusable menstrual cups used for one year have less than $1.5 \%$ of the environmental impact of disposable sanitary products. A study by Makov et al. [41] showed that waterdispensing stations (e.g., Woosh) have the potential to reduce the adverse environmental impacts associated with the consumption of bottled water. Similar conclusions were drawn by Stajcer et al. [42] in a study on refillable bottles, which showed that they have better environmental performance than single-use bottles made from $50 \%$ recycled material. In addition, a study by Landi et al. [43] showed that the reuse of glass bottles subject to industrial cleaning, refill, and distribution in a local economy has better environmental performance than recycling. 


\section{Method}

A dataset of reuse offerings in the FMCG industry was collected and analysed to address the research aim. Section 3.1 presents the data collection. Section 3.2 presents the analysis of the data to characterise the reuse models. Section 3.3 presents the analysis of the data to characterise the capability of the reuse models to deliver environmental value.

\subsection{Data Collection}

The dataset investigated in this study includes ninety-two cases of reuse offerings (Figure A1 in Appendix A). In order to be included in the dataset, cases had to comply with the following criteria. First, they had to be representative of a business-to-consumer model operating within the FMCG market, and provide the consumer with an opportunity to reuse (i.e., recurrently utilise an FMCG for its original purpose). Cases of both reusable packaging and products were considered suitable to be studied because they fit with the aim to understand the reuse of FMCGs and were developed to replace traditional lowinvolvement and short-lived goods. Moreover, reusable FMCG packaging and products are comparable in terms of their journey as material resources and the interactions that consumers have with them. Hence, they can be used to characterise generic reuse models. Given that reuse is a strategy in its early stages and not many reusable FMCGs exist, cases from different sectors and markets were included in the dataset. If analysed to identify how the goods move in a system and how individuals interact with them, cases from multiple sectors and markets are comparable and have already been studied as a dataset in prior research [44]. The inclusion of such cases is also due to the fact that large FMCG companies are global and therefore tend to implement new reuse models across different geographical areas. It is worth noting that this study considered the FMCG sector and market as a whole and did not aim to characterise differences between reuse across sub-sectors and specific markets. Finally, cases had to include information about the material resources embodied in the goods to be able to assess the environmental value proposition.

The search for cases involved identifying brands and businesses compliant with these criteria. This was carried out using the Zero Waste Living Lab database [45], reuse literature $[25,44]$, and internet searches (using search term combinations such as "reuse" + " $<$ FMCG product type $>$ " or "<FMCG category $>$ "). Subsequently, each identified case was researched (by accessing the offering website) to obtain information on the design of the reuse offering, namely the key reuse system elements. This information was gathered between September 2019 and March 2020.

The final set of selected reuse offerings is representative of several common types of FMCGs, namely beverages $(n=37)$, foods $(n=27)$, personal care products $(n=25)$, home care products $(n=18)$, baby care products $(n=5)$, and transit packaging $(n=4)$ (some offerings in the sample operated across several FMCGs categories). In the dataset, $88 \%$ are offerings centred on the reuse of durable packaging, whereas the remaining $12 \%$ are centred on the reuse of durable products. Hence, in the forthcoming sections of the paper, the term "product" is used as a general descriptor of both durable packaging (i.e., vessels, such as bottles) and durable products (i.e., non-packaging goods, such as nappies). At the time of data collection, these offerings served domestic consumer markets in Europe $(n=42)$, North America $(n=19)$, Asia $(n=7)$, South America $(n=3)$, Australia $(n=3)$, Africa $(n=2)$, and worldwide $(n=17)$. Overall, $28 \%$ of the offerings in the sample operated internationally, i.e., they served consumers in more than one country.

Individual cases of reuse business-to-consumer offerings operating within the FMCG market are cited throughout the paper as examples, and the sources (i.e., website addresses) can be located in Figure A1 (Appendix A).

\subsection{Data Analysis: Emergence of the Reuse Models}

The analysis followed two stages. In the first, the reuse offerings were mapped individually to identify their reuse system elements, namely the architectural components (i.e., people, objects, and infrastructures) that have a central role in facilitating reuse. The 
reuse system elements identified and investigated in this study include the (1) reuser behaviour, (2) reusable product, and (3) reuse-enabling infrastructure.

The reuser behaviour describes the consumption interaction with the reusable product. Building on previous work of Tukker [46] and Wieser [47] and the data analysed in this research, two types of reuse behaviour modes were identified, namely exclusive reuse and sequential reuse. Exclusive reuse behaviour is that of a consumer or a household who consumes individually and keeps the reusable product. Sequential reuse behaviour is that of a consumer or a household who consumes along with multiple successive individuals and returns the reusable product. Exclusive reuse behaviour involves individual and unlimited access, while sequential reuse behaviour involves sharing through successive access.

The reusable product is an FMCG equivalent that has been redesigned from a singleuse and disposable product to a multi-use and long-life product. Two types of reusable product were identified, namely a reusable product (i.e., one that is used directly by the consumer) and a reusable assistive product (i.e., one that aids the consumption). The reusable products are either durable packaging or durable products, which are typically composed of two key components, the consumable and the facilitator. For durable packaging, such as a reusable beverage bottle, the bottle itself is the facilitator, and the beverage is the consumable. Whereas for durable products, such as a reusable nappy, the nappy outer wrap is the facilitator and the nappy inner cloth liner is the consumable. The function of the consumable is to fulfil a specific consumption need (e.g., in a reusable bottle, the function of the beverage is to hydrate; and in a reusable nappy, the function of the liner is to absorb), while the function of the facilitator is to enable the consumable to deliver its function (e.g., the function of the bottle is containment of the beverage, and the function of the nappy outer wrap is containment of the liner).

Furthermore, two types of provision of the reusable product were identified, namely provided or not provided. In the majority of the offerings, the reusable product was provided. However, in some offerings, the reusable product was not provided, and the offerings involved access to refill the infrastructure with a previously owned reusable product. The reusable product was also distinguished on the basis of its readiness for consumption through two modes, namely "ready for consumption" and "in need of preparation". Finally, two types of consumption for a reusable product were identified as in Wieser [47], namely ownership (consumer-owned) and access (provider-owned; see Appendix B).

The reuse-enabling infrastructure refers to the system that supports the reuse of the reusable product. Two types of reuse-enabling infrastructure were distinguished, namely preparation infrastructure and recovery infrastructure. In terms of preparation for reuse, two types of infrastructure were identified, namely assistive product and assistive appliance. More so, two types of infrastructure organisation were identified, namely provided by the supplier and consumer-operated (within the consumption phase; see Appendix C) and relied upon by the consumer but provider-operated (outside the consumption phase). In the first type, the consumer directly uses the infrastructure, whereas in the second type, the system requires the infrastructure, but it is not consumer facing.

The second stage of the analysis consisted of identifying current reuse models, namely commercial offerings built upon a specific configuration of reuse system elements, which provide the consumer with an ability and opportunity to reuse. Offerings with the same sets of reuse system elements were grouped by commonality to help identify distinct reuse models. A similar approach was also adopted by the EMF [25], where types of consumer behaviour and locations were used to define different reuse models.

The reuse system elements for three offerings from the beverage category are shown in Figure 1. Offering A and offering B both involve a reusable product. However, the reuser behaviour is different, i.e., exclusive and sequential. Further, offering B provides consumers with reuse-enabling infrastructure, while offering A does not. As a result, they are different reuse models: offering A sits in the exclusive reuse model 1, whereas offering B sits in the sequential reuse model 5 . In contrast, offering $B$ and offering $C$ show common key reuse 
system elements, which indicates that they belong to the same reuse model. The results of this analysis are presented in Section 4.

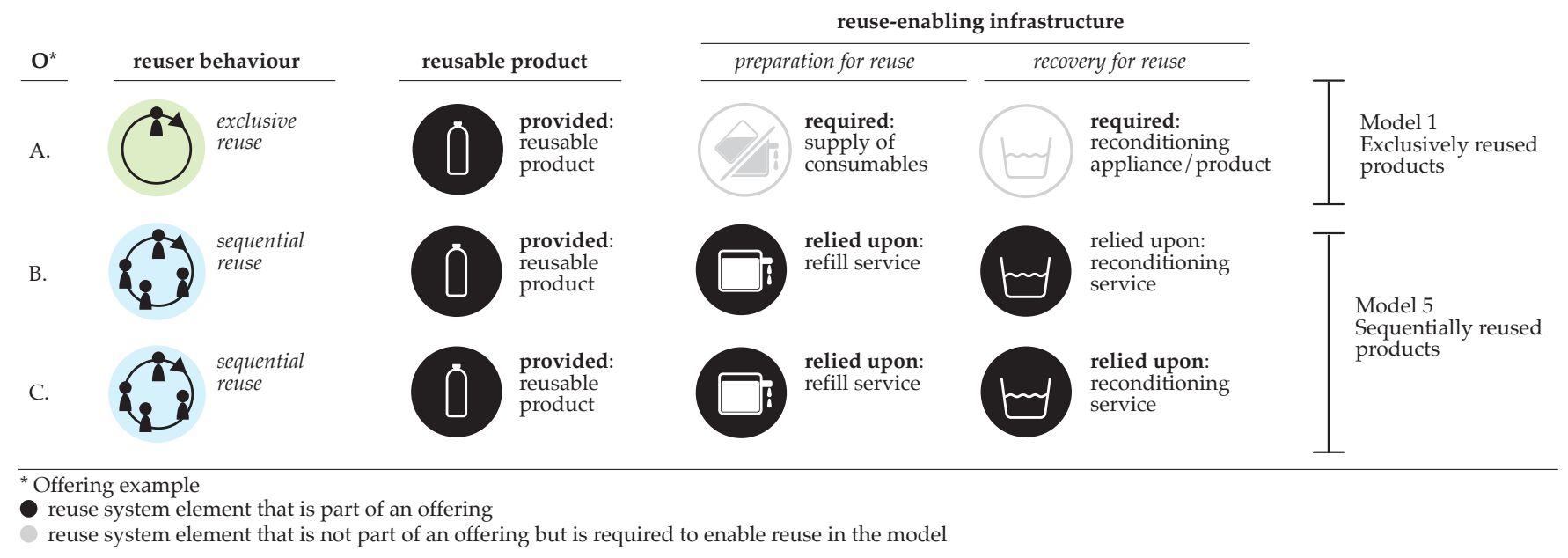

Figure 1. Examples of analysis of reuse offerings: (A) Dopper, (B) Vessel Works, (C) Loop.

\subsection{Data Analysis: Evaluation of Environmental Value Proposition of the Reuse Models}

Using an early-stage qualitative approach, the reuse models were evaluated to establish their Environmental Value Proposition (EVP), namely the pathways to deliver sustainable and resource-efficient outcomes [37]. The EVP factors used in the evaluation are based on a framework proposed by the European Environment Agency (EEA) [48] as applied in Manninen et al. [37] to evaluate the EVP of circular business models. However, the factors in the EEA framework are only partially defined, making an objective assessment of the reuse models challenging. To resolve this issue, each factor was assigned "realisation methods" (i.e., system approaches by which the environmental value can be achieved) identified by literature review. Notably, this process also consisted of selecting the factors for which evidence of fulfilment or non-fulfilment was available in the literature, as this would ensure that the assessment was factual. For example, categories of factors such as fewer material losses and reduced emissions were excluded, as they specify further outcomes of delivering the six EVP factors (e.g., fewer materials losses can be achieved by delivering factors F3 and F4 and reduced emissions by delivering factors F1, F2, F5, and F6), which could not be estimated (see Table 2). Hence, whilst Manninen et al. [37] used the full list of EVP factors from the EEA [48], this study only includes six factors split into three categories, as presented in Table 2. Importantly, the six EVP factors used in this study are distinguished depending on whether they relate to either the product or infrastructure of an offering.

The evaluation of the reuse models involved scoring their capability to achieve the EVP factors and comparing them against the linear model currently operating in the FMCG industry. This process was carried out in two stages. In the first stage, the capability to achieve the EVP factors by the current linear model and the reuse models was determined by the authors and justified based on evidence from the literature on FMCGs and sustainability. The evaluation uses a scheme where models are scored to have either a high capability to deliver the EVP factor (+) or a low capability to deliver the EVP factor (-). In the second stage, a comparative evaluation of the reuse models against the linear model was performed, where the differences between the individual reuse models and the linear model are highlighted. This aimed to reveal which models perform better in delivering a specific EVP factor. In past circular economy research, a similar methodology involving scoring models has been used by Tukker [46] to establish the economic value of product-service systems (PSS). Other research by Manninen et al. [37] conducted a qualitative evaluation of the EVP of circular offerings compared to disposable goods. 
Table 2. Environmental Value Proposition (EVP) factors.

\begin{tabular}{|c|c|c|c|c|c|}
\hline ID & EVP Factors ${ }^{1}$ & $\mathrm{E}^{2}$ & Realisation Methods $^{3}$ & Linear Model ${ }^{3,4}$ & \\
\hline \multicolumn{6}{|c|}{ Less input and use of natural resources ${ }^{5}$} \\
\hline F1 & $\begin{array}{l}\text { Minimised and optimised } \\
\text { exploitation of raw materials, } \\
\text { while delivering more value } \\
\text { from fewer materials }\end{array}$ & $\mathrm{P}$ & 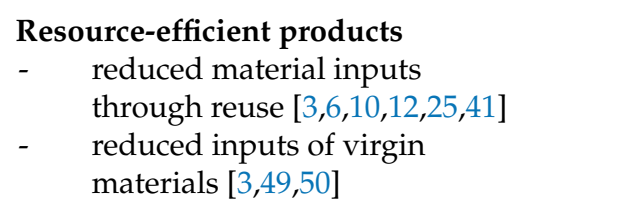 & $\begin{array}{l}\text { - } \quad \text { FMCGs are made for single-use rather than to reuse. } \\
\text { Light-weighing methods are increasingly adopted to achieve resource } \\
\text { efficiency [6]. Nevertheless, the FMCG sector still makes extensive } \\
\text { utilisation of virgin materials due to the large market and } \\
\text { growing population. }\end{array}$ & - \\
\hline $\mathrm{F} 2$ & $\begin{array}{l}\text { Minimised overall energy } \\
\text { and water use }\end{array}$ & I & $\begin{array}{ll}\text { Resource-efficient processing } \\
-\quad & \text { increased use of } \\
\text { reconditioned components }[3,25,41] \\
\text { - } & \text { shortened distribution }[3,6,41,51]\end{array}$ & $\begin{array}{l}\text { - FMCGs are made for single-use rather than to recondition reusable } \\
\text { components. Manufacture of FMCGs is resource-intensive, due to the } \\
\text { processing of materials, the production methods and the large market. } \\
\text { Distribution of FMCGs is energy-intensive due to the long-distance and } \\
\text { frequent transportation (e.g., high food miles) [43] and freight load } \\
\text { inefficiencies (e.g., underutilised weight and volume capacity } \\
\text { of vehicles) [52]. }\end{array}$ & - \\
\hline \multicolumn{6}{|c|}{ Increased share of renewable and recyclable resources and energy ${ }^{5}$} \\
\hline F3 & $\begin{array}{l}\text { Increased share of recyclable } \\
\text { and recycled materials that } \\
\text { can replace the use of } \\
\text { virgin materials }\end{array}$ & $\mathrm{P}$ & $\begin{array}{l}\text { Longevity of materials } \\
\text { - } \quad \text { increased use of recycled } \\
\text { material inputs }[6,49,50,53] \\
\text { - } \quad \text { increased use of recyclable } \\
\text { material inputs }[6,49,50,53] \\
\text { - } \quad \text { ease of material separation }[50,53,54] \\
\text { - } \quad \text { recycling behaviour }[7,55]\end{array}$ & $\begin{array}{l}\text { - Recycled materials are used in FMCGs but currently not on a large scale; } \\
\text { extensive use of virgin raw materials by the industry continues [4]. } \\
\text { - } \\
\text { Recyclable and non-recyclable materials are used. } \\
\text { Use of adhesives, coatings, ink and composites limits separation of } \\
\text { recyclable materials in FMCGs and causes contamination }[8,54] \\
\text { - } \quad \text { Inappropriate disposal behaviours lead to recyclable materials flowing out } \\
\text { of the economy and being lost to landfill, incineration and environment. }\end{array}$ & - \\
\hline $\mathrm{F} 4$ & Closure of material loops & I & 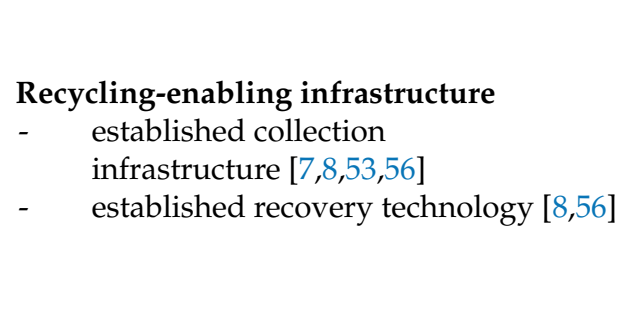 & $\begin{array}{l}\text { - Collection infrastructure for recyclables is established, and end-of-life } \\
\text { FMCGs are retrieved for recycling, although kerbside infrastructure is } \\
\text { insufficient to allow for collection of all types of recyclable materials. } \\
\text { Material recovery technologies are established; however, their capacity to } \\
\text { process some material types (e.g., black plastics identification and } \\
\text { contaminated loads) is limited [54,56]. Ultimately as much as } 80 \% \text { of } \\
\text { materials from post-consumer FMCGs are diverted to landfill } \\
\text { and incineration [3]. }\end{array}$ & +- \\
\hline
\end{tabular}


Table 2. Cont.

\begin{tabular}{|c|c|c|c|c|c|}
\hline ID & EVP Factors ${ }^{1}$ & $\mathrm{E}^{2}$ & Realisation Methods ${ }^{3}$ & Linear Model 3,4 & \\
\hline \multicolumn{6}{|c|}{ Keeping the value of products, components and materials in the economy ${ }^{5}$} \\
\hline F5 & $\begin{array}{l}\text { Extended product lifetime } \\
\text { keeping the value of products } \\
\text { in use }\end{array}$ & $\mathrm{P}$ & $\begin{array}{l}\text { Longevity of products } \\
\text { - } \\
\text { increased material and } \\
\text { structural durability to } \\
\text { extend lifespans }[6,49,50,57,58] \\
\text { - } \quad \text { increased use of modularity for } \\
\text { component replacement }[49,57,58] \\
\text { - } \quad \text { reuse behaviour (e.g., emotional durability } \\
\text { [58], person-product relationship [59], } \\
\text { product stewardship [32,60], and product } \\
\text { perceptions, e.g., towards quality [32]) }\end{array}$ & $\begin{array}{l}\text { - The durability of FMCGs is limited to facilitating single-use (e.g., flexible } \\
\text { film packaging, mixed fibre-based sanitary products can only be used once } \\
\text { and cannot be recovered for reuse). } \\
\text { - Component replacement is not commonly adopted in the recovery } \\
\text { of FMCGs. } \\
\text { - Short lifespans of FMCGs are a barrier to consumer performing } \\
\text { reuse behaviour. }\end{array}$ & - \\
\hline F6 & Reuse of components & I & $\begin{array}{l}\begin{array}{l}\text { Reuse-enabling infrastructure } \\
-\quad \\
\text { established infrastructure for } \\
\text { preparation for reuse }[10,24,25,61]\end{array} \\
\text { - } \quad \begin{array}{l}\text { established collection infrastructure } \\
\text { for reuse }[25,61]\end{array} \\
\text { - } \quad \text { established recovery infrastructure } \\
\text { for reuse [25,61] } \\
\text { Reuse-driving system mechanisms } \\
-\quad \begin{array}{l}\text { increased financial incentives } \\
\text { for reuse [25,50,55,57] }\end{array} \\
\text { - } \quad \text { increased subscriptions for reuse [25] }\end{array}$ & $\begin{array}{l}\text { FMCGs are made for single-use rather to be prepared for reuse. Dispensing } \\
\text { infrastructure exist, however it is often used with single-use FMCGs. } \\
\text { Collection infrastructure mostly retrieves end-of-life FMCGs for recycling, } \\
\text { rathe than reuse. } \\
\text { Recovery infrastructure is limited to recycling of end-of-life FMCGs and } \\
\text { does not support recovery for reuse. } \\
\text { - Low price mark makes frequent replacement of single-use FMCGs easier } \\
\text { and more affordable than reuse with incentives. } \\
\text { - Subscriptions commonly involve scheduled re-purchase of single-use } \\
\text { FMCGs rather than reusables. }\end{array}$ & - \\
\hline
\end{tabular}

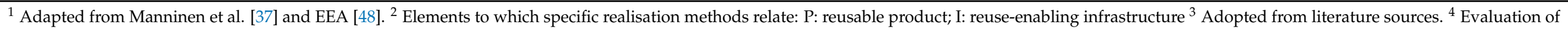

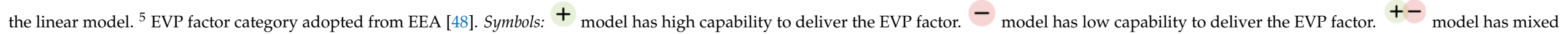
(high-low) capability to deliver the EVP factor. 
The EVP factors, realisation methods, and the evaluation of the linear model are presented in Table 2. The results of the EVP analysis are presented in Section 5.

\section{Reuse Models}

Based on the analysis, five main reuse models and their variants were identified. Each of the models is characterised by a specific configuration of three types of reuse system elements, namely the (1) reuser behaviour, (2) reusable product, and (3) reuse-enabling infrastructure. An overview of the reuse models is presented in the framework in Figure 2. The model names were chosen based on how the configurations of system elements enable the reuse of a product. It is worth noting that all the models involve durable packaging reuse, with some models extending to also involve durable product reuse.

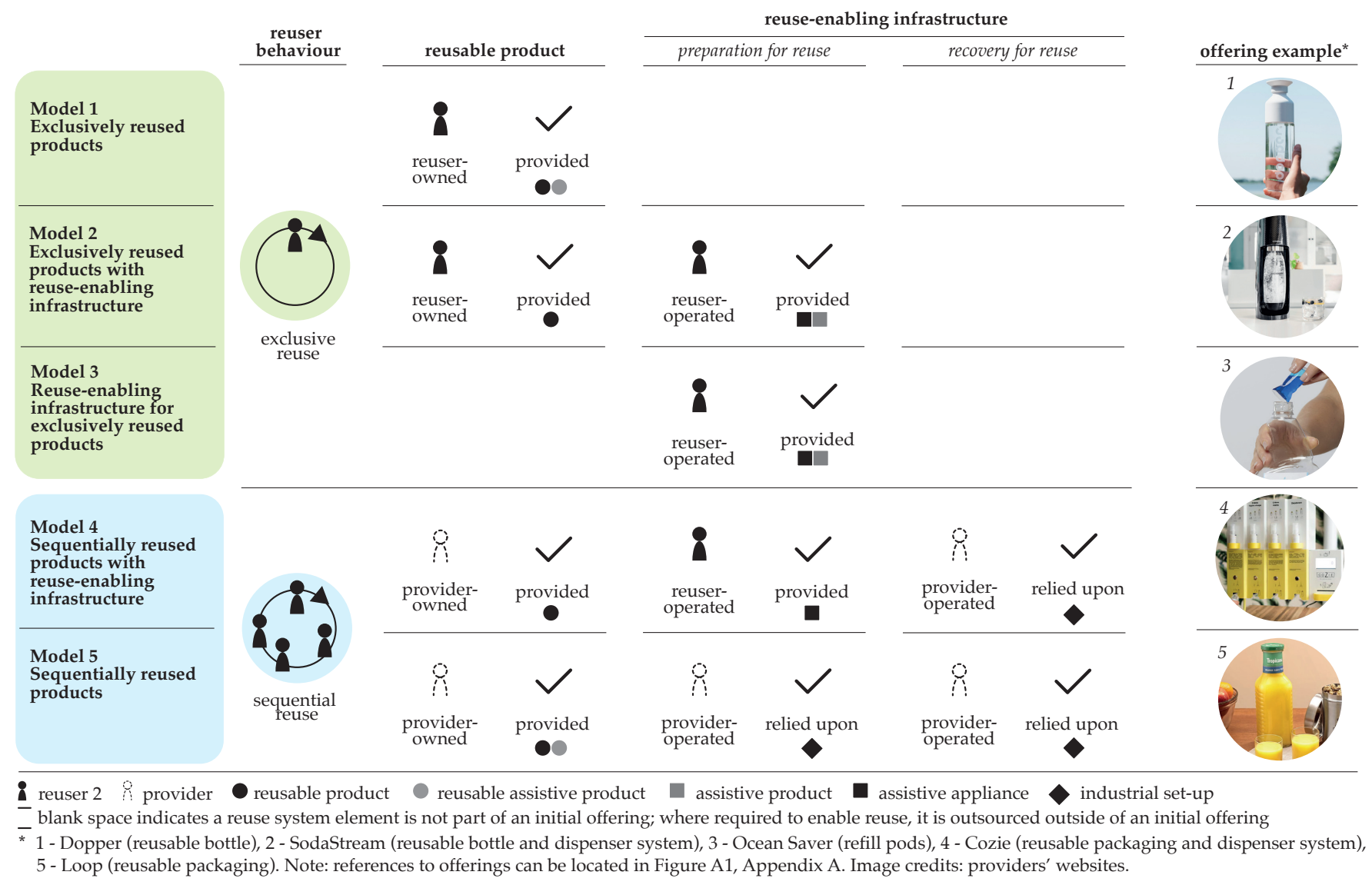

Figure 2. Reuse models framework.

The first type of system element, reuser behaviour, divides the reuse models into two groups. The first group includes three models in which consumers exclusively reuse products, whereas the second group includes two models in which consumers sequentially reuse products. The second type of system element, reusable product, distinguishes the models based on ownership of the product, i.e., reuser-owned or provider-owned. It also indicates whether a reusable product, i.e., reusable product or a reusable assistive product, is provided or not. Finally, the third type of system element, reuse-enabling infrastructure, allows further distinction between the models based on the infrastructure provided for the preparation and recovery of reusable products. Preparation for reuse is performed on an already recovered reusable product with the intention to consume, and it typically involves refilling or replenishing the reusable product with a consumable. Preparation for reuse infrastructure can either be consumer-operated within the consumption phase through the use of an assistive product (e.g., Ocean Saver refill pouch, 3, Figure 2) and /or an assistive appliance (e.g., SodaStream dispenser, 2, Figure 2), or provider-operated outside of 
the consumption phase, through an industrial set-up (e.g., refill service provided for Loop packaging, 5, Figure 2). Recovery for reuse is performed post-consumption on a product with the intention to reinstate it to a usable condition. Recovery for reuse infrastructure can similarly either be consumer-operated within the consumption phase, through the use of an assistive product (e.g., detergent) and/or an assistive appliance (e.g., washing machine), or provider-operated outside of the consumption phase through an industrial set-up (e.g., industrial cleaning of packaging provided by Cozie, 4, Figure 2).

Sections 4.1 and 4.2 further define exclusive and sequential reuse and present the variants of each of the main models. Individual cases of business-to-consumer reuse offerings are cited throughout the following sections and can be located in Figure A2 (Appendix D).

\subsection{Exclusive Reuse Models}

This section presents models in which durable FMCGs are exclusively reused (Figure 3). Exclusive reuse is a behaviour by which a reusable product is recurrently used by a single user throughout the product lifetime for the same purpose for which it was conceived, and with the support of reuse-enabling infrastructure.

In exclusive reuse models, the user owns (or accesses; see Appendix E) the reusable products. The user keeps the product and is responsible for its recovery for reuse and subsequent reintroduction in the consumption phase. The pattern of "utilisation-recovery-preparation" repeats up until the reusable product is no longer fit for use, or the reuser decides to stop using the product.
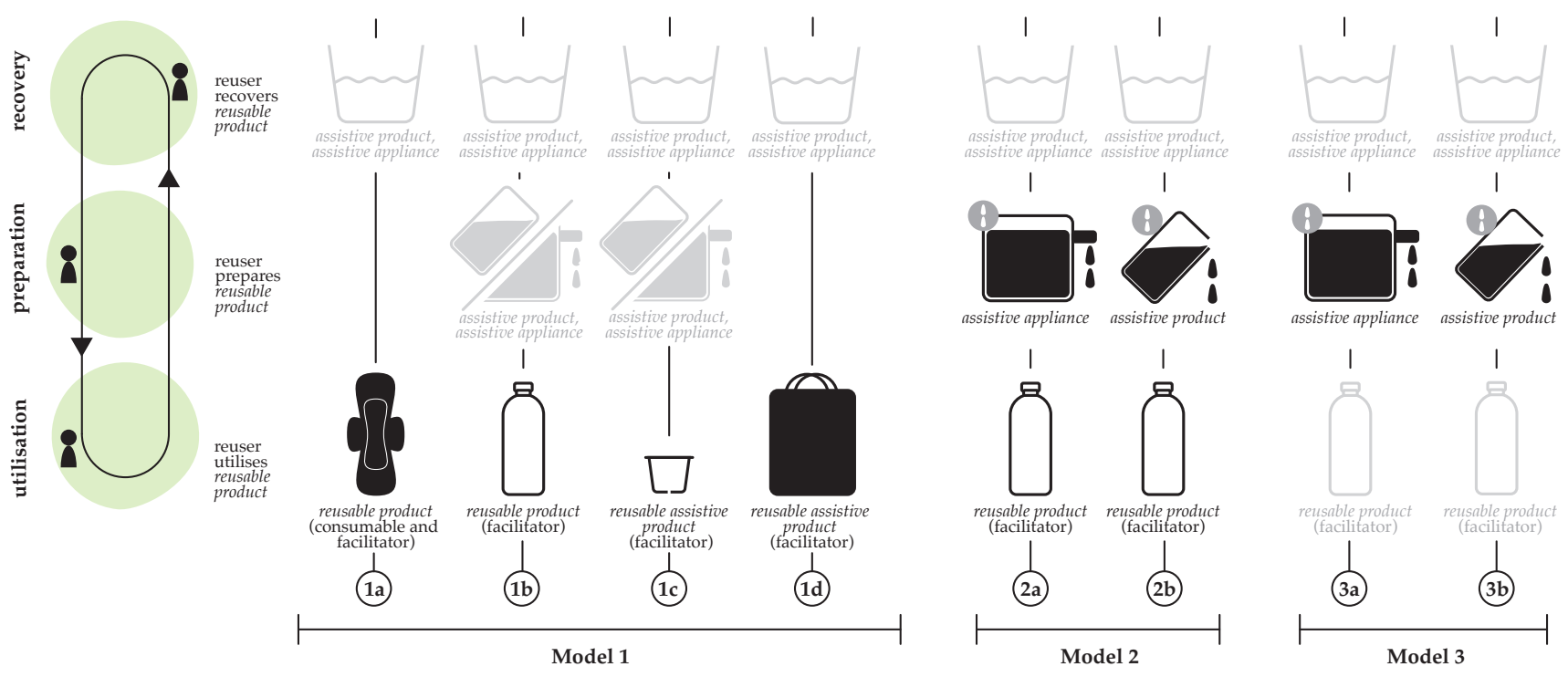

reuser

reuse system element that is part of an offering

reuse system element that is not part of an offering but is required to enable reuse in the model

(1) additional preparation for reuse infrastructure that is not part of an offering but in some offerings is required to enable reuse in the model

Figure 3. Models of exclusive reuse.

Three main reuse models-model 1, 2, and 3 (and their variants) — that adopt this type of reuse have been identified, as illustrated in Figure 3.

\subsubsection{Model 1: Exclusively Reused Products}

Model 1 represents offerings that provide consumers with a reusable product only. This can be either a reusable product (i.e., one that is consumed directly by the consumer; $1 \mathrm{a}$ and $1 \mathrm{~b}$, Figure 3 ) or a reusable assistive product (i.e., one that aids the consumption of an FMCG; 1c and 1d, Figure 3). More so, the reusable product is offered either in a "ready for consumption" state or in an "in need of preparation" state. "Ready for consumption" means that no additional preparation for reuse is required for the product to be utilised by 
the consumer. In contrast, "in need for preparation" means that the consumer is required to operate reuse-enabling infrastructure to prepare the reusable product for utilisation.

This model has four key variants based on the type of product and the way in which it is offered, which are (1a) reusable product "ready for consumption", $(1 \mathrm{~b})$ reusable product "in need of preparation", (1c) reusable assistive product "in need of preparation" and (1d) reusable assistive product "ready for consumption".

Model 1a. A reusable product "ready for consumption" is a durable good (i.e., equivalent to single-use consumer goods) delivering utility to the consumer. An example is durable cloth sanitary towels (e.g., Bloom and Nora, image 1 in Figure A2, Appendix D), which are composed of a consumable (an absorption layer) and a facilitator (structural layer), both of which are reusable. The consumables of products belonging to this model are typically made of non-perishable materials (e.g., fabrics) that are durable enough to withstand multiple uses.

Model 1b. A reusable product "in need for preparation" is a durable vessel (i.e., equivalent to single-use primary packaging) requiring the supply of a consumable to be used. An example is a refillable bottle (e.g., Dopper, image 2 in Figure A2), which facilitates the consumption of a beverage sourced using infrastructure available to the consumer (e.g., a water dispenser). The consumables held in products within this model are typically made of perishable materials (e.g., beverages), which can be used up or decay over time.

Model 1c. A reusable assistive product "in need for preparation" is a component of a reuse-enabling infrastructure necessary to prepare consumables. An example is durable cartridges (e.g., coffee pods WayCap, image 3 in Figure A2), which are refilled with ground coffee and inserted into a compatible coffee machine to prepare a beverage.

Model 1d. A reusable assistive product "ready for consumption" is transit packaging already containing all the key utility-enabling components to deliver its function. An example is durable shopping bags (e.g., Onya, image 4 in Figure A2) used to transfer consumer goods between locations.

In fact, the recurring utilisation of reusable products is dependent on recovery for reuse. In all model 1 variants, recovery for reuse is always initiated by a consumer, and it involves them using infrastructure (e.g., dishwasher, washing machine) that they have access to. In most cases, the recovery process involves the consumer cleaning the product in order to bring it back to a usable condition. Other recovery activities can include the consumer replacing a broken component to prolong the product life (e.g., the provider of the modular Dopper bottle sells individual replacement components).

\subsubsection{Model 2: Exclusively Reused Products with Reuse-Enabling Infrastructure}

Model 2 represents offerings that provide consumers with an interconnected system composed of a reusable product and reuse-enabling infrastructure, both of which are part of the same offering. In this model, the reusable product is always offered in an "in need for preparation" state, and its primary function is to facilitate the consumption of a consumable supplied by the reuse-enabling infrastructure.

This model has two key variants, based on the type of reuse-enabling infrastructure used to prepare the consumable, which are as follows: (2a) reusable product and assistive appliance, and (2b) reusable product and assistive product (Figure 3). In this model, the interfaces between the reusable product and the infrastructure are commonly designed to enable conjoint operation. In some cases, this can lead to the preparation of reusable products being restricted to the use of the infrastructure provided by a single brand (e.g., Replenish reusable spray bottles and refill cartridges are designed to be used exclusively together, image 5 in Figure A2).

Model 2a. In the interconnected system composed of a reusable product and an assistive appliance, the latter is typically a machine that contains bulk consumables dispensed in finished and ready to consume or concentrated form. The consumer can have individual (e.g., at home) or shared (e.g., in a shop) access to the assistive appliance. Where the consumer has individual access to the assistive appliance, they need to source the bulk consumables for 
dispensing. In some cases, particularly where the consumable dispensed from an appliance is insufficient to make an end product (e.g., a beverage), the consumer is required to access additional consumables (e.g., water) that are not provided within the initial offering. An example is the kitchen beverage maker SodaStream (assistive appliance, image 6 in Figure A2) that combines carbon dioxide, flavouring, and water in order to prepare a beverage and consume it from a durable bottle. In contrast, where the consumer has shared access to the assistive appliance, they are not required to perform additional activities in order to make the appliance work for the preparation of a consumable. This is set up by the provider, and the consumer only utilises the assistive appliance for the purpose of replenishing the reusable product. An example is in-store dispensers that supply food into parented durable vessels (e.g., Miwa, image 7 in Figure A2).

Model $2 \mathrm{~b}$. In the interconnected system composed of a reusable product and an assistive product, the latter supplies a consumable component to the reusable product. The consumable can be supplied either in finished and ready to consume or in concentrated form. When the consumable is supplied in finished form, it does not require the input of additional consumables in order to deliver its function. In this instance, the preparation activities are typically fulfiled through the reusable products and assistive products provided in the offering. An example is durable vessels supplied with refill pods containing the finished consumable (e.g., face creams such as Olay Whip, image 8 in Figure A2). Another example is durable nappy covers supplied with single-use absorption liners (e.g., Billie Wonder, image 9 in Figure A2). In contrast, when the consumable is supplied in a concentrated form, the preparation activities can extend to include interaction with infrastructure available outside of the initial offering (e.g., water dispenser). An example is reusable bottles supplied with a concentrated consumable in a refill pod (e.g., a flavouring syrup) that has to be diluted in water (e.g., Drinkfinity, image 10 in Figure A2).

In addition, similarly to model 1, the recurring utilisation of products in this model is dependent on their recovery for reuse. This is not provided in the offering but is expected to be performed by the consumers, who have to access reuse-enabling infrastructure for recovery by themselves. In most cases, the recovery process involves the consumer cleaning the product in order to bring it back to a usable state.

\subsubsection{Model 3: Reuse-Enabling Infrastructure for Exclusively Reused Products}

Model 3 represents offerings that provide consumers with reuse-enabling infrastructure only to support the preparation of a reusable product. In this model, the reusable product is not supplied by the provider. Instead, it is purchased and brought by the consumer to be used as a facilitator to access a consumable from the infrastructure. Therefore, similarly to model 2, the reusable product is always "in need for preparation", as its primary function is to facilitate the consumption of a supplied consumable.

This model has two key variants based on the type of reuse-enabling infrastructure used to deliver the consumable, which are (3a) an assistive appliance and (3b) an assistive product (Figure 3). Typically, the infrastructure provided in this model is designed to work with diverse types of reusable products, meaning that the interfaces between them give consumers flexibility to use different brands (unlike in model 2).

Model 3a. The assistive appliance is typically a machine that contains bulk consumables and is used to dispense them into the reusable product. Similarly to model 2, the consumer can have either individual access or shared access to the assistive appliance. Where the assistive appliance is individually owned, the consumer is required to supply the appliance with bulk consumables. An example is domestic water dispensers (e.g., Evian Renew, image 11 in Figure A2). In contrast, where the consumer has shared access to the assistive appliance, they are not required to perform additional activities in order to make the appliance work other than to use it to replenish reusable packaging. An example is dry food dispensers (e.g., Unpackaged refillery, image 12 in Figure A2) or water dispensers (e.g., Woosh, image 13 in Figure A2). 
Model 3b. The assistive product supplies a consumable component into the reusable product, either in a finished and ready to consume or concentrated form. Similarly to model 2 where the consumable is supplied in concentrated form, specifically for liquid consumables, the preparation activities are typically supported by additional external infrastructure (e.g., water dispenser). An example is refill pouches that supply reusable bottles with detergents in concentrated form (e.g., Ocean Saver Eco Drops, image 14 in Figure A2).

\subsection{Sequential Reuse Models}

This section presents models in which durable FMCGs are sequentially reused. Sequential reuse is a behaviour by which a reusable product is used consecutively by multiple users throughout the product lifetime for the same purpose for which it was conceived, and with the support of reuse-enabling infrastructure.

In sequential reuse models, the user has access to a reusable product. The user is responsible for returning the reusable product to the provider, who is then responsible for its recovery for reuse and subsequent reintroduction in the consumption phase for another user. The pattern of "utilisationrecovery-preparation" repeats up until the consumer does not return the product, the reusable product is no longer fit for use, or the provider decides to stop offering the product.

Two main reuse models-model 4 and 5 (and their variants)— that adopt this type of reuse have been identified, as illustrated in Figure 4.
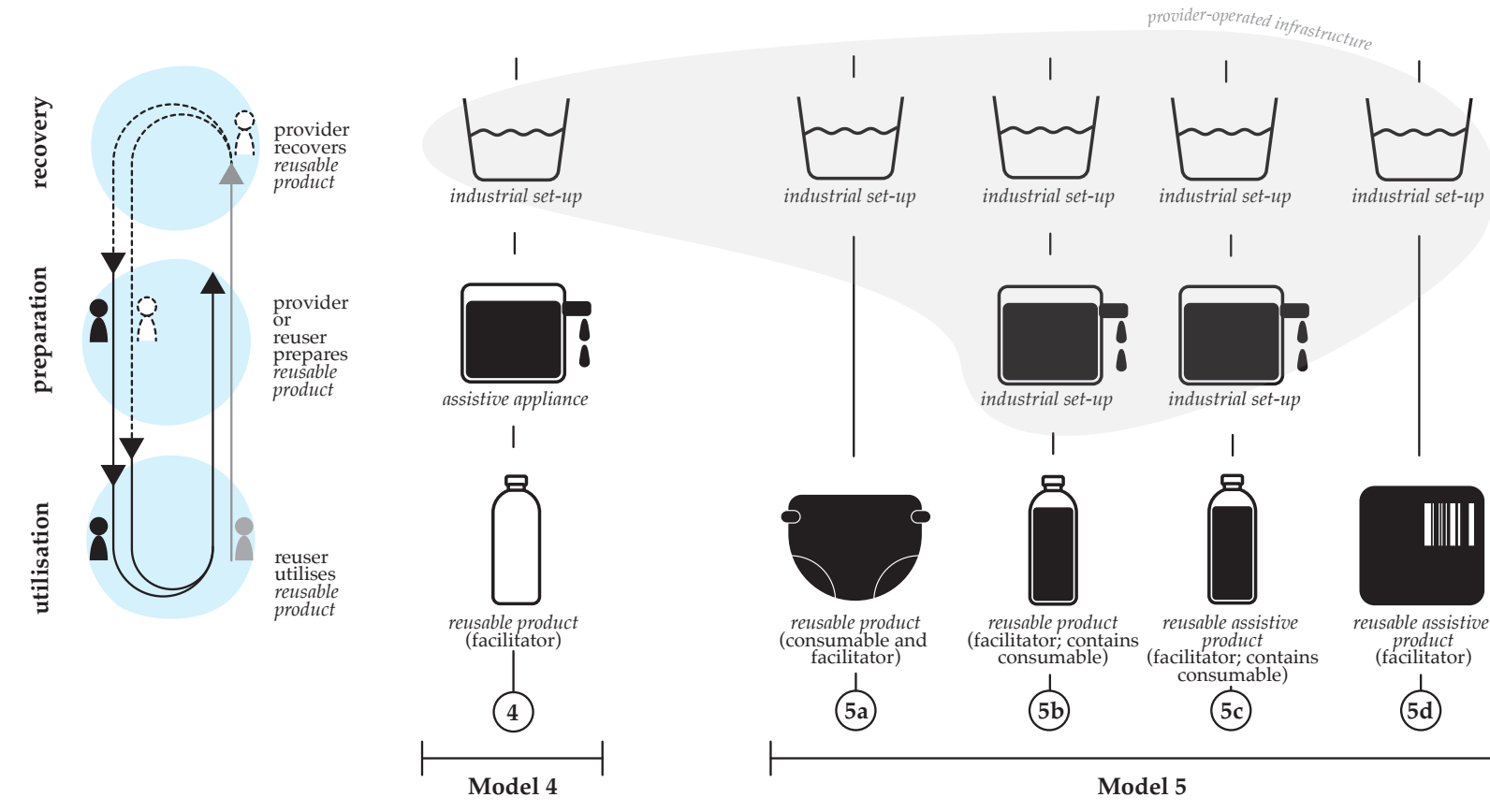

Model 4

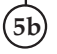

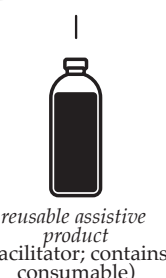

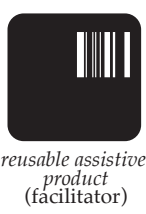

(5)

Model 5

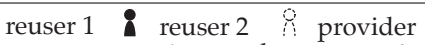

reuse system element that is part of an offering

reuse system element placed outside of the consumption phase

Figure 4. Models of sequential reuse.

\subsubsection{Model 4: Sequentially Reused Products with Reuse-Enabling Infrastructure}

Model 4 represents offerings that provide consumers with an interconnected system that is composed of a reusable product and reuse-enabling infrastructure, all of which are part of the same offering (4, Figure 4$)$.

This model has one variant, which is an interconnected system composed of a reusable product, a consumer-operated assistive appliance for preparation for reuse, and a provideroperated industrial set-up for recovery for reuse.

When provided to the consumer, the reusable product is always in an "in need for preparation" state. It commonly functions as a durable vessel that requires the supply 
of a consumable in order to be utilised as a facilitator for acquisition and consumption. The assistive appliance is used by the consumer to deliver a consumable into the reusable product. This tends to be shared among consumers, who are provided with temporary access to it. An example is in-store dispensers used to refill skincare products into parent reusable and returnable vessels (e.g., Cozie refill, image 15 in Figure A2). Similarly to model 2, the interfaces between the product and infrastructure are standardised for their conjoint operation.

The repeated utilisation of the reusable products is dependent on their recovery for reuse. Unlike exclusive reuse models, this model relies upon the recovery of reusable products by the provider through reuse-enabling infrastructure, namely an industrial set-up that is deployed outside of the consumption phase. The recovery typically involves cleaning the product with the aim to bring it back to a usable state. This process commences with the consumer returning the reusable product at a specific location, such as the place of initial purchase (e.g., a shop).

\subsubsection{Model 5: Sequentially Reused Products}

Model 5 represents offerings that provide consumers with a reusable product only. This can be either a reusable product ( $5 \mathrm{a}$ and $5 \mathrm{~b}$, Figure 4 ) or a reusable assistive product ( $5 \mathrm{c}$ and $5 \mathrm{~d}$, Figure 4). More so, the reusable product is always offered in a "ready for consumption" state; when provided to the consumer, it already contains all of the key utility-enabling components. This is due to both recovery and preparation for reuse being performed by the provider using a reuse-enabling infrastructure deployed outside of the consumption phase.

This model has four key variants based on the type of product and the infrastructure offered, which are as follows: (5a) reusable product with provider-operated reuse-enabling infrastructure for recovery only, $(5 b)$ reusable product with provider-operated reuse-enabling infrastructure for both preparation and recovery, (5c) reusable assistive product with provider-operated reuse-enabling infrastructure for both preparation and recovery, and (5d) reusable assistive product with provider-operated reuse-enabling infrastructure for recovery only.

Models $5 \mathrm{a}$ and $5 \mathrm{~b}$. The reusable product is typically either a durable good or vessel utilised by individual consumers in sequence and retrieved by the provider after each use for recovery and preparation (where required) before being reintroduced in the market. The need for the provider to perform reuse depends on the type of consumable contained within the reusable product. In model $5 \mathrm{a}$, this is made of non-perishable and durable materials (e.g., fabrics) that can withstand multiple uses. This means that no preparation processes are needed to enable product reuse. In model $5 b$, the consumable is made of perishable materials (e.g., foods) designed to deliver a single use cycle. This means that it is used up or decays during that cycle, needing replenishment to enable product reuse by another consumer in the next cycle. Regardless of the consumable types, the facilitator is always a durable component of a reusable product designed for multi-use. An example of model $5 \mathrm{a}$ is sequentially reused baby diapers where both the consumable and facilitator are made of reusable fabrics (e.g., Washcot, image 16 in Figure A2). An example of model 5b is sequentially reused durable vessels (i.e., facilitators) containing foods (i.e., consumables) (e.g., Loop, image 17 in Figure A2).

Models $5 \mathrm{c}$ and $5 \mathrm{~d}$. The reusable assistive product is a durable product or packaging used to aid the consumption of another product and retrieved by the provider after each use for recovery and preparation (where required) before being reintroduced in the market. The need for the provider to perform reuse depends on the type of consumable contained within the reusable assistive product. In model $5 c$, a reusable assistive product functions as a component of the reuse-enabling infrastructure necessary to make consumables. The consumables in this type of assistive product (similarly as in model $5 b$ ) are typically perishable and therefore can deliver only a single use cycle and need to be replenished to enable product reuse by another consumer in the next cycle. An example is a durable SodaStream gas canister (reusable assistive product, image 18 in Figure A2) that is a 
component of a dispenser (assistive appliance) used to produce a beverage; once emptied, the gas canister is returned to the provider for refill before it can re-enter the consumer market. In model $5 \mathrm{~d}$, a reusable assistive product is presented as one that does not require preparation for reuse by the provider. The reusable assistive product is typically a transit packaging that contains all the key utility-enabling components (i.e., facilitator) to deliver its function. An example is durable delivery packaging used for goods transported to and from consumers; the bag is returnable to the provider (with or without its original contents) for recovery and reintroduced in the market to be reused in subsequent goods delivery (e.g., RePack, image 19 in Figure A2).

In addition, the reuse of the products also relies upon their recovery post-consumption. Similarly to model 4 , the recovery is part of the initial offering, meaning that following its return by a consumer, the product is recovered by the provider. The recovery typically involves cleaning the product or replacing its broken components with the aim to bring it back to a usable state. This is enabled by reuse-enabling infrastructure, namely the industrial set-up, that is deployed outside of the consumption phase and typically commences with the consumer returning the reusable product to a specific location (e.g., a shop, a doorstep, a return bin) from which it is retrieved and transferred to by the provider.

\subsection{Multi-Model Offerings}

Some offerings are based on multiple models of reuse. These provide consumers with more than one way to reuse. This section presents a summary of the two types of multi-model offerings identified-multi-model options and multi-model combinations (Figure 5).

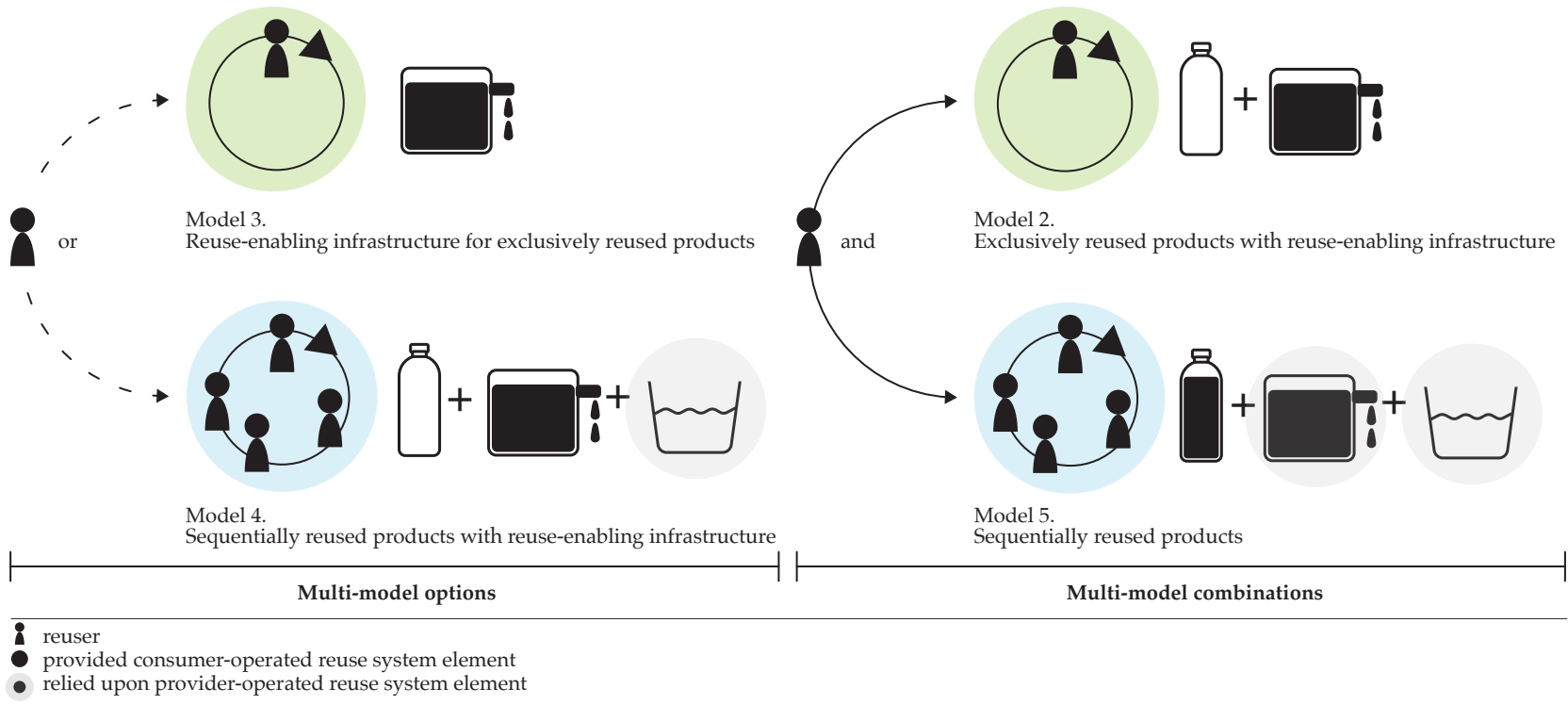

Figure 5. Multi-model offerings: options and combinations.

\subsubsection{Multi-Model Options: Providing Consumers with Several Pathways to Reuse}

Some offerings allow consumers the choice to reuse a product exclusively or sequentially. For example, some food refill station companies (e.g., Waitrose and Partners Unpacked [62]; left, Figure 5) provide the exclusive reuse option, allowing consumers to refill reusable vessels that they already own using the provider's in-store dispensers (model 3), as well as the sequential reuse option, allowing consumers to borrow vessels from the provider before refilling it using the in-store dispenser (model 4).

In addition, some offerings allow consumers to reuse across multiple models but limit it to one type of reuse, either exclusive or sequential. For example, some food refill station companies (e.g., Miwa) provide the exclusive reuse option, where consumers can use an 
in-store dispenser by utilising a reusable product purchased either from the provider of the dispenser (model 2) or elsewhere (model 3).

4.3.2. Multi-Model Combinations: Increasing Reusability of Several Products in an Offering

In some offerings, the consumer is required to simultaneously reuse several reusable products, both exclusively and sequentially. For example, SodaStream consumers (right, Figure 5) exclusively reuse the bottle (reusable product) that is refilled using the assistive appliance (model 2), and also sequentially reuse the pre-filled gas canister (assistive product) received from the provider to be used with the assistive appliance to prepare a beverage (model 5).

In addition, some offerings require the consumer to reuse across multiple models but limit it to one type of reuse, either exclusive or sequential. For example, some perishable goods delivery companies (e.g., Loop) require consumers to sequentially reuse several elements of their offering, such as the refillable vessels (reusable product; model 5b) and the reusable transit packaging totes (reusable assistive product; model $5 \mathrm{~d}$ ). In multi-models of sequential reuse where transit packaging is reused as well as vessels, several elements can form a system-internal dependency, where the reuse of one element influences the reuse of another. For example, the sequential reuse of transit packaging used to deliver goods to the consumer influences the ability to return reusable products for sequential reuse. At the same time, the return of a reusable product to the provider influences the sequential reuse of the transit packaging.

\section{Environmental Value Proposition of Reuse Models}

This section presents a qualitative assessment of the capability of the reuse models to deliver environmental value, which is summarised in Table 3.

Table 3. The Environmental Value Proposition (EVP) of five reuse models.

\begin{tabular}{|c|c|c|c|c|c|c|c|c|}
\hline \multirow{2}{*}{ ID } & \multirow{2}{*}{ EVP Factors } & \multirow{2}{*}{$\mathrm{E}^{1}$} & \multicolumn{3}{|c|}{ Exclusive Reuse } & \multicolumn{2}{|c|}{ Sequential Reuse } & \multirow{2}{*}{ Linear Model $^{2}$} \\
\hline & & & Model 1 & Model 2 & Model 3 & Model 4 & Model 5 & \\
\hline \multicolumn{9}{|c|}{ Less input and use of natural resources } \\
\hline $\mathrm{F} 1$ & $\begin{array}{l}\text { Minimised and optimised } \\
\text { exploitation of raw } \\
\text { materials, while } \\
\text { delivering more value } \\
\text { from fewer materials }\end{array}$ & $\mathrm{P}$ & + & + & + & + & + & - \\
\hline F2 & $\begin{array}{l}\text { Minimised overall energy } \\
\text { and water use }\end{array}$ & I & + & + & + & + & + & - \\
\hline \multicolumn{9}{|c|}{ Increased share of renewable and recyclable resources and energy } \\
\hline F3 & $\begin{array}{l}\text { Increased share of } \\
\text { recyclable and recycled } \\
\text { materials that can replace } \\
\text { the use of virgin materials }\end{array}$ & $\mathrm{P}$ & $-\bullet$ & - & $-\bullet$ & $-\bullet$ & $-\bullet$ & - \\
\hline F4 & Closure of material loops & I & +- & +- & $+-^{\bullet}$ & + & + & +- \\
\hline \multicolumn{9}{|c|}{ Keeping the value of products, components and materials in the economy } \\
\hline F5 & $\begin{array}{l}\text { Extended product lifetime } \\
\text { keeping the value of } \\
\text { products in use }\end{array}$ & $\mathrm{P}$ & + & + & + & + & + & - \\
\hline F6 & Reuse of components & I & + & + & + & + & + & - \\
\hline
\end{tabular}

${ }^{1}$ Elements to which specific EVP factors relate: P: reusable product; I: reuse-enabling infrastructure. ${ }^{2}$ Evaluation derived from Table 2.

Symbols: + model has high capability to deliver the EVP factor. - model has low capability to deliver the EVP factor. +- model has mixed (high-low) capability to deliver the EVP factor. • capability to deliver the EVP factor is similar to the linear model. 


\subsection{Less Input and Use of Natural Resources}

5.1.1. F1. Minimised and Optimised Exploitation of Raw Materials, While Delivering More Value from Fewer Materials

The reuse models have a greater capability to achieve this EVP factor than the linear model. This is because although reusable products tend to be made using a larger volume of resources per unit compared to single-use FMCG equivalents, the durable design allows using them over a number of use cycles significantly greater than single-use products. This highlights the aptitude of reuse models to reduce material volumes over time in comparison to single-use FMCGs in the linear model $[4,6,13]$ and ultimately decreases the overall volume of materials flowing in the system from virgin sources. For example, one FaceHalo durable make-up removal pad can replace up to 500 single-use pads [63], and one durable food packaging unit (e.g., Loop system) can replace up to 100 single-use units [61].

The exploitation of raw materials in reusable products can also be minimised through using recycled materials. This issue is discussed further in section F3.

\subsubsection{F2. Minimised Overall Energy and Water Use}

The reuse models have a greater capability to achieve this EVP factor than the linear model. This is because reusable products can generate savings on energy and water used during manufacturing and distribution.

In the linear model, FMCGs are single-use, and their production typically uses significant amounts of energy and water to satisfy ongoing consumer demand. Reuse models rely on infrastructure that allows FMCGs to be used recurrently by the same consumer (exclusive reuse) or to be recalled, reconditioned, and reinstated in the market (sequential reuse). Therefore, in reusable products, the use of durable components reduces the requirement for energy and water in comparison to manufacturing frequently and from "scratch" [3,38,40,42,43]. For example, in exclusive reuse models, the availability of food dispensers (e.g., London Unpackaged) enables the consumer to use reusable vessels multiple times, thereby reducing the overall energy required to manufacture them compared to single-use packaging. In sequential reuse models (e.g., Loop system), the reuse-enabling infrastructure includes a tote used to facilitate the return of soiled durable vessels from the consumer to the provider. Once retrieved, the provider carries out a reconditioning process including industrial cleaning and reassembly of vessels for refill, which also require less energy than to manufacture new goods. In terms of impact on energy and water used in production, it is also important to note that both in exclusive and sequential reuse models, more than one reusable product per consumer is likely to be needed to satisfy recurrent needs. For example, in sequential reuse models, a "buffer quantity" of reusable products is required to manage the delay between consumer return and delivery and ensure that demands are met in a timely manner.

In the linear model, distributing globally produced single-use FMCGs to consumers is an energy-intensive process, which is chiefly due to the long-distance and frequent transportation of goods between the provider and consumer [64,65]. For perishable goods, this has to be coupled with the use of energy for refrigeration in the transportation. Furthermore, freight load inefficiencies (e.g., underutilised vehicle space and weight capacity) often cause an overconsumption of fuel [52]. In both exclusive and sequential reuse models, the consumables in reusable products are also typically globally produced and therefore have to travel long distances to reach various consumer markets around the globe. However, in some cases, the consumables are produced and traded locally, and this can significantly reduce energy impact due to transportation and associated fuel consumption $[6,41,51,66]$. For example, in a sequential reuse model such as Vessel Works, the reuse-enabling infrastructure for the recovery and preparation of durable beverage vessels operates within the perimeters of a single town. The vessels are transported from the provider to a coffee shop, where they are prepared for reuse, utilised, and deposited by the consumer in a public return bin and retrieved by the provider for recovery at a nearby washing facility [67]. Nonetheless, 
scaling up such local recovery and preparation for reuse platforms for all types of goods poses major infrastructural and financial challenges.

Some single-use FMCGs, such as beverages, home care, and personal care products are commonly distributed with the consumables and ready for consumption. Comparatively, reuse models, in particular exclusive reuse models 2 and 3, and sequential reuse model 4 , provide the consumer with infrastructure (assistive products and appliances), which supplies consumables for reusable products. This infrastructure commonly uses either bulk or concentrates, resulting in reduced product volumes and loads due to less packaging and more efficient transportation (e.g., less trips required) to the market. For example, the concentrated consumables in the Cif Ecorefill assistive product can reduce $80 \%$ of the trucks used for the distribution of the bottled ready for consumption detergents to market [68]. Another example is the reuse-enabling infrastructure in SodaStream, which allows savings in transportation, as one gas canister containing carbon dioxide can be combined with tap water (sourced locally to the place of preparation), producing 60 litres of beverage [69].

\subsection{Increased Share of Renewable and Recyclable Resources and Energy}

5.2.1. F3. Increased Share of Recyclable and Recycled Materials That Can Replace the Use of Virgin Materials

The reuse models, similarly to the linear model, have a low capability to achieve this EVP factor. This is because reusable products are not commonly made of materials that are recycled and/or recyclable.

The recyclability of materials in reusable products varies; whilst some are fully recyclable, it is common for reusable products to be either partly recyclable or not recyclable at all. For example, insulated double-wall stainless steel reusable bottles are not commonly collected at kerbside with single-use discarded FMCGs because they cannot be crushed and baled for ease of transport in Material Recovery Facilities (MRFs); hence, they need to be disposed of at designated specialist reuse and recycling facilities for processing. The inability to recycle at the kerbside is a concern, as it can lead consumers to incorrectly dispose of valuable and recyclable materials into landfill [7,55]. Another example of a hard-to-recycle and widely used material is borosilicate, which is a shutter and heat-resistant glass composite that is often used in reusable vessels. The material causes contamination and ultimately diminished quality of the common glass stream, as they are difficult to separate [70,71].

The content of recycled materials in reusable products also varies. Some providers offer reusable products made solely of recycled materials. However, it is also common that solely virgin or a mix of virgin and recycled materials are used to maintain high material quality and adhere to safety standards. For example, plastics used in Dopper reusable bottles are currently never sourced from recycled materials due to the risk of contamination with harmful chemicals (e.g., BPA, BPS, lead, phthalates, adhesives). Instead, virgin plastics are used as they are considered to be purer and therefore safer [72]. For the same reason, silicones, such as the medical-grade used in reusable menstrual cups (e.g., ZeroCup) and the food-grade used in reusable packaging (e.g., Stojo coffee cups), are also derived from virgin resources.

\subsubsection{F4. Closure of Material Loops}

The capability to deliver this EVP factor is key in a circular economy [73] and varies between exclusive and sequential reuse models. Sequential reuse models have a greater capability to achieve this EVP factor than the linear model and exclusive reuse models.

With regard to the exclusive reuse models, some offerings give the consumer an option to return their end-of-life reusable products to the provider for recycling (e.g., FaceHalo make-up removal pads [63]). However, in the majority of cases in this model, consumers are not offered services to return products for recycling. In exclusive reuse models, the material collection and recovery processes mostly depend on infrastructure that is available to consumers outside of the offering. A key issue is that MRF technology is limited to recycling specific types of materials, chiefly to facilitate the processing of end-of-life single- 
use and disposable FMCGs, as well as to produce an end product cost-effectively [74]. Therefore, reusable products that have the potential to be recycled are not commonly collected for recovery via kerbside; instead, consumers are required to dispose of their reusable products at designated remote locations, which serve as alternative gateways to revalorisation [75].

In sequential reuse models, the return infrastructure has a greater capability to ensure a closed loop material flow as the provider drives the process and consumers are held accountable. In these models, the decision on whether a reusable product or its components has reached its end of life is made by the provider, who has a higher capacity (e.g., knowledge of material content in a product and partnerships with recyclers of hard-torecycle/not-widely recycled materials) to dispose of products correctly and ensure their recovery. For example, returned reusable products provided by Loop are diverted by the provider for recycling once they pass their useful life.

\subsection{Keeping the Value of Products, Components, and Materials in the Economy}

\subsubsection{F5. Extended Product Lifetime Keeping the Value of Product in Use}

All of the reuse models have a greater capability to achieve this EVP factor than the linear model. This is because reusable products are designed for longevity and therefore, their value can be extended over multiple uses.

Material and structural durability (e.g., resistance to use conditions, such as exposure to extreme temperatures, deformation risks, and degradation due to contact with other substances) are key technical specifications to extend lifetime [50,57,58]. Durability is central because reusable products have to endure ongoing processes of recovery for reuse, which commonly involve cleaning, using water, detergents, and high temperatures. For example, the durable materials used in reusable sanitary towels (e.g., natural and synthetic fabrics) have to withstand several washing-machine cycles and maintain their utility, unlike their single-use equivalents.

Modular design is important to facilitate component replacement, as it can enable both the provider (in sequential reuse) and the consumer (in exclusive reuse) to replace individual components in reusable products, further extending their functional life [50,58,76]. For example, Dopper (in the exclusive reuse model) is a three-part modular bottle, where each part can be individually obtained and replaced by the consumer.

To mitigate adverse consumer perceptions towards reuse, the providers of reusable packaging are also employing novel product design strategies. For example, it has been proposed to treat the surfaces of reusable products to make them "age gracefully" (e.g., a product surface shows a new pattern in response to wear and tear) [61]. Moreover, in exclusive reuse models where reusable products are owned and play a vital role in daily consumption routines (e.g., on-the-go beverage consumption from reusable bottles), consumers can develop attachment and sense of care, which enhances product lifetimes [77]. Differently, in the sequential reuse model, the emotional durability of reusable products might entail that the individual consumer cares about the wider community of consumers. This can motivate product stewardship through careful handling and return of shared products for the benefit of the successive reuser $[32,60]$.

\subsubsection{F6. Reuse of Components}

Reuse models have a greater capability to achieve this EVP factor than the linear model. This is because reuse models are purposely designed to support reuse and involve processes of preparation and recovery as core activities to extend the utilisation of reusable products. The reuse-enabling infrastructure has a crucial role in enabling these processes $[10,24]$.

The reuse of durable FMCGs always depends on the use of recovery for reuse infrastructure, which assists the reconditioning (e.g., cleaning, washing) of the reusable product with the aim of bringing it back to its useful state. Whilst this process is key to every reuse model, it is currently not facilitated by the providers of exclusive reuse offerings. However, exclusive reuse models, products are commonly designed to fit the recovery processes performed by 
the consumer, such as the use of common assistive products and appliances (e.g., washing machines, detergents) that are available to them outside of the initial offering. Whereas in sequential reuse models, the provider takes the responsibility of recovering reusable products. This is enabled through an industrial set-up (e.g., cleaning facilities), where the provider cleans post-consumer reusable products before reintroduction in the economy. For example, the reusable vessels employed by Loop are safely sanitised in their cleaning facilities [61] before being refilled and sent to the next consumer.

In addition, the reuse of reusable products, particularly where they are used as facilitators to the consumption of perishable consumables, strongly depends on the availability of infrastructure for preparation for reuse. This entails the delivery (e.g., making and refilling) of consumables to the product in order for it to be reused. Models 2 and 4 provide infrastructure that is part of interconnected refill systems. Model 3 provides infrastructure with standardised interfaces to supply consumables to various types of reusable products. This infrastructure is commonly available to the consumer either permanently (e.g., full ownership of an appliance, such as SodaStream) or temporarily (e.g., sharing of an appliance, such as London Unpackaged shop dispenser). Differently, in sequential reuse model 5 , the provider takes the responsibility of preparing reusable products for reuse. This is enabled through an industrial set-up (e.g., bottling line) commonly used to make and/or refill the content of recovered durable vessels with consumables before reintroducing them on the market.

Another contributor to reuse models having a greater capability to achieve this EVP factor than the linear model are mechanisms such as reward and deposit schemes and subscriptions to encourage consumers to reuse. Reward schemes are effective drivers for reuse [55], and these are commonly present in exclusive reuse models where consumers are provided with tangible incentives (e.g., loyalty points, discounts) each time they reuse a product. For example, Algramo provide consumers with loyalty points for refilling reusable vessels, which can be used as discounts for the next purchase. Deposit schemes are commonly present in sequential reuse models, where consumers pay an additional fee (e.g., up-front deposit) for the products they borrow as an incentive for the return of products for reuse. For example, Vessel Works [67] requests a $\$ 15$ up-front payment when lending their reusable cups to the consumer, which is paid back upon its return at a drop-off bin. Subscriptions to an offering are also a mechanism that enhance consumer adoption of reuse models [25]. For example, Humankind subscribers receive reusable vessels that they obtain within the first purchase, and scheduled deliveries of refills thereafter.

\section{Discussion}

The pressure on resource supply and the environmental impact of linear consumption systems are an urgent call for the FMCG industry to shift towards a circular economy. Governments are beginning to disincentivise linear consumption (e.g., by enforcing taxes on single-use plastic packaging [78]) and are urging businesses to embrace alternative waste prevention strategies such as reuse (UK Government [79], European Commission [80,81]). The FMCG industry, with businesses ranging from start-ups to large corporations, is starting to recognise the importance of shifting to a circular economy (e.g., the UK Plastics Pact [82], CE100 Members Network [83]) and is introducing reuse practices into their offerings. Research into FMCGs reuse systems is growing, particularly for packaging. Recent work on reuse systems has predominantly organised offerings based on reusable packaging models (e.g., [24]) and users' actions such as refill and return [25]. However, to date, research into the system elements and processes that facilitate reuse has been lacking.

This research bridges this knowledge gap by providing a framework for comprehensive characterisation of the main reuse models currently operating in the FMCG industry. The framework establishes key reuse system elements, their functions, and the configurations currently adopted in the industry. It also characterises core reuse behaviours that consumers perform for different types of reusable product and how they are enabled by various types of infrastructure. 


\subsection{Two Behavioural Modes to Reuse FMCGs: Exclusive Reuse and Sequential Reuse}

The reuse models currently adopted by the FMCG industry enable consumers to practice reuse in two behaviour modes: exclusive reuse and sequential reuse. In both modes, reuse entails three key operations: preparation of a reusable product for reuse, reuse of a reusable product, and recovery of a reusable product for reuse (as shown in Figures 3 and 4, left). These operations are macro-level components of a wider reuse behaviour chain that spans across several stages of the journey taken by reusable products through the system [84].

In exclusive reuse models, reusable products are kept and owned by consumers controlling their journey through the system. The preparation, utilisation, and recovery operations are always performed by consumers. An advantage of these models is that consumers utilise products and perform the recovery themselves (e.g., cleaning). In this way, they are in control of the conditions of the products as opposed to sequential reuse models, where products are shared. On the other hand, a disadvantage of these models is that they require substantially greater consumer effort in comparison to the linear model (where products are made "ready for consumption" and easily replaced following their disposal) [85]. As shown in previous studies on the behavioural determinants of using reusable packaging (e.g., $[29,30])$, consumers' perceptions towards the effort involved in performing a reuse behaviour can influence behavioural intention to participate in such offerings.

In sequential reuse models, reusable products flow in sequence from one consumer to the next (via the provider), and consumers are offered access to the products before returning them back for subsequent reuse. The provider takes the responsibility for some of the behaviours in the reuse chain (as illustrated in Figure 4), reducing consumers' effort. In model 4 , the preparation and utilisation are performed by the consumer, while the provider performs the recovery. Differently, in model 5, both the preparation and recovery are performed by the provider. The ultimate reduction in consumer effort can be seen in model 5, where products arrive to consumers' homes in a "ready for consumption" state (e.g., supplied with consumables) and can be returned from consumers' homes (e.g., doorstep collection), thereby giving consumers a level of convenience similar to or even seemingly exceeding that of the linear model [28]. Nonetheless, the methods of return for recovery provided in this model vary. Therefore, the level of consumer effort can range from low (e.g., returning via the doorstep at home) to high (e.g., returning in an in-store drop off location, which may be far from home) [75]. In model 4, the issue of effort required for preparation is raised as the consumer is commonly required to perform necessary preparation activities (e.g., refill) using provided infrastructure. A general disadvantage of sequential reuse is the negative perception towards the cleanliness and quality of post-consumer products, which can influence consumer intention to reuse $[55,86]$.

In summary, businesses have a choice to offer two key behavioural modes to consumers. Exclusive reuse is a route to utilise reusable products for consumers who value ownership, are happy to invest effort, and do not want to risk the potential adverse perceptions of sequential reuse. Whereas sequential reuse, pending its advancement, is a platform for consumers that prefer access and value convenience when utilising reusable products.

\subsection{The Lives of Reusable Products Are in the Hands of the Consumer}

The consumer is ultimately responsible for correctly guiding products through the consumption system $[1,84]$. This includes ways in which they obtain, utilise and dispose of products. Exclusive reuse models are currently designed to give the consumer freedom to decide how long they keep and reuse their products. The consumer can choose to utilise a reusable product multiple times up until it reaches the end of its useful life or to utilise it for a number of times that is insufficient to offset its environmental impacts $[87,88]$. In the latter case, the reusable product can be stored and underutilised or prematurely disposed of [10]. The longevity of reusable products in exclusive reuse models can also be affected by inappropriate handling by the consumer, particularly in the processes of preparation and recovery. For example, the use of detergents and high temperatures during the recovery of reusable bottles can cause their deformation (e.g., Dopper reusable plastic bottle [89]). 
At the end of life, reusable products are commonly destined to enter municipal waste streams. Despite some providers accepting post-consumer goods for recycling, whether reusable products enter the correct waste stream is dependent on consumers' decisions to appropriately dispose of them [10].

Sequential reuse models are more likely to include mechanisms (e.g., financial incentives, subscriptions) that can influence consumers' decisions to perform necessary behaviours. The up-front costs invested, e.g., deposit on reusable products, give the provider some control over the product journey, as they can lure resources by nudging the consumer [90] to return products for recovery and further reuse. For example, a higher deposit value can increase the recovery rate [91]. However, financial incentives and subscriptions can influence but not enforce or guarantee consumer behaviour. Hence, consumers may decide to bear the loss of deposits and dispose of reusable products instead.

In summary, when implementing reuse into practice, a business must be aware that consumer engagement with the appropriate use and disposal of reusable products is critical to ensure success. Sequential reuse presents an opportunity to better control the flow of products at the end of use, which is when they are returned to the provider. Nonetheless, it still poses a challenge in guaranteeing that the correct consumer behaviours are performed. Exclusive reuse presents a higher potential for system errors (e.g., reduced product lifetime, redirection into landfill instead of recycling) due to the direction of the flow being less governed and in the hands of consumers.

\subsection{The Design of Reusable Products Needs to Improve to Close Material Loops}

Whilst reuse models have been identified to have a significantly higher potential to bring environmental value than the linear model, EVP factors F3 and F4 from the category of "increased share of renewable and recyclable resources and energy" remain unsatisfied. The FMCG industry needs to improve their approach to the design of reusable products in order to close the loops of material flows. Some providers ensure that the material content of their reusable products is recycled and recyclable. However, they are often produced using virgin (e.g., fossil-based plastics) and non-widely recyclable materials (e.g., composites) which, if not carefully managed at the end of life, generate negative impacts on the environment [10]. In addition, some businesses justify the use of virgin and high-performance materials (e.g., stainless-steel and reinforced glass) in reusable products by highlighting that their environmental footprint can be offset over a prolonged period of use. However, to move towards a "true" circular economy, i.e., one that captures and circulates materials in the system, the industry needs to implement design strategies that increase recycled and recyclable material content and ensure the easy separation of materials for subsequent processing [50]. This also has to be coupled with the design of a system that fosters correct disposal behaviours by the consumer $[1,55,84]$.

In summary, a business has to carefully consider the design of reusable products to ensure that materials can be recovered through current recycling systems. Simultaneously, efforts should be made to advance current collection infrastructure and recovery technology to enable the recycling of materials from reusable products.

\subsection{Reusable FMCGs Become "Slow-Moving Consumer Goods" and Require System-Wide Change}

It is not uncommon for the term "fast" in FMCGs to refer to the speed at which products are produced and delivered to the market [92] or the dynamics of supply chains that are able to rapidly change to address new consumer needs in tastes and trends [93,94]. However, in the context of the linear economy, the term can also be interpreted as the rate at which goods that are disposed and re-purchased on a regular basis due to a short lifespan $[95,96]$, implying that fast-moving indicates the speed at which products in the linear model flow through the economy.

In reuse models, FMCGs satisfy everyday consumer needs using the same product (i.e., durable packaging and/or durable product) over multiple uses, significantly slowing down the replacement rate. This suggests that FMCGs can be seen becoming "slow-moving". 
Sustaining reusable products limit the industry to change the design of FMCGs, which is a common approach to rapidly respond to new consumer needs [92,93]. However, to slow down the replacement rate, the industry faces different supply chain challenges. This study has identified that preparation and recovery infrastructures are paramount to enable the consumption of reusable products. In many reuse offerings, the consumer is required to interact with shared infrastructure (e.g., in-store dispensers) or not interact with infrastructure at all while receiving the outcome of its utility (e.g., a factory-refilled product). In these instances, the preparation and recovery functions are fulfilled through the provision of services, highlighting that reusable products exist within systemic structures that are typical of product-service systems (PSS) [46,97]. As a result, "slow-moving" FMCGs supported by services challenge the current supply chain to evolve in order to support reuse in the industry.

In current FMCG supply chains, production systems are typically centralised with globally integrated operations and long distribution channels. This allows the industry to achieve economies of scale and cuts costs by eliminating inefficient and redundant processes. However, this structure poses logistical challenges for the movement of reusable products. Any reorganisation of the supply chain to serve a new reuse economy requires consideration of production systems, distribution networks, and operations management to enable reusable products to move through the system more sustainably [15].

For exclusive reuse models, current production systems and distribution channels to retailers still have the capability to support reuse. In fact, the industry is already conducting pilots, which demonstrate the capability of the current supply chain to distribute consumables in bulk. These pilots centre on supplying long-life consumables, such as dry foods, cosmetics, and beverages to retailers for further distribution to the consumer via local in-store dispensers. Nonetheless, bulk dispensing systems are underdeveloped for several other consumable types. For example, current technology is expected to pose challenges to the delivery of consumables, such as harsh detergents and refrigerated or perishable foods due to safety, spoilage, and contamination risks. With respect to agricultural goods, such as seasonal foods, the current supply chain, which uses a mix of global and regional production and long or short distribution channels, can utilise reusable tertiary packaging for bulk distribution to retailers [98] or directly to consumers.

In order to enable preparation for reuse operations by consumers, the current off-theshelf supermarket format and consumable-dispensing infrastructure will need substantial development and investment. There are several barriers for businesses considering the adoption of such infrastructure in stores. These include an increase in shop floor costs due to the requirement to display several elements of an offering (e.g., a dispenser and stock of refillable containers) and a potential increase in employee costs, due to the extra number of staff needed to run refill points, which are often slower than off-the-shelf sales [99].

For sequential reuse models, product manufacturing systems could also remain unchanged. However, new regional facilities to clean and replenish reusable products (i.e., durable packaging and/or products) need to emerge in close proximity to the consumer market. If recovery and preparation for reuse operations involve long-distance trips, as some pilot sequential reuse systems currently do, there is a risk that the carbon footprint associated with transportation negatively impacts the environmental costs of reuse $[15,100]$. Currently, the capability to carry out recovery and preparation for reuse processes at a local level exists mainly for take-away food and hot beverages. For these goods, preparation and recovery are performed in close proximity to consumers and by a single stakeholder (e.g., a restaurant) or through a partnership of several stakeholders (e.g., a coffee shop, a provider's cleaning facility) located within the remit of a small economy (e.g., a town).

With regard to recovery for reuse operations specifically, supply chains require a new infrastructure for the collection of reusable products and careful consideration of the associated operational costs $[15,63]$. The collection infrastructure can be designed on the basis of who owns reusable containers and is responsible for their recovery [15]. If the infrastructure is shared and therefore serves the recovery of products that belong to 
several providers, communal reuse bins for recovery and industrial-cleaning facilities could emerge. The introduction of communal reuse bins would require various FMCG businesses to collaboratively approach the design of reusable products to enable their standardised collection and sorting. This collaborative approach would also need to apply to the reverse logistics system, ensuring that products are returned to the correct providers (e.g., product tracking and identification technology can be adopted [15]). It would require substantial enhancements to identify and sort a highly complex variety of products. Technology is emerging to support such advanced identification, for example through watermarks (e.g., the Holy Grail Project [101]) or object recognition technology [102]. Nevertheless, the implementation of this technology requires systemic and collaborative change. Although a business-to-business relationship in reverse logistics can be easier to manage than businessto-consumer, in practice, a lot of inefficiencies occur due to customer non-compliance [103]. Whilst a shared product recovery infrastructure is likely to be beneficial, it could also make the management of operations more complicated due to the high volume of deliveries and pick-ups [15].

In addition, current kerbside recycling bins commonly collect only a selection of products and materials from post-consumer single-use and disposable FMCGs. Hence, another important infrastructural transformation involves the extension of these schemes to include the collection of materials from post-consumer reusable products to enable them to enter the correct recycling stream. It must be reviewed whether reusable products can be correctly and economically identified and sorted by current MRF technology [104], and the collected materials can still be transitioned to future uses [72]. This is needed for reusable products in exclusive reuse only if they do not offer an end-of-life collection service. For sequential reuse, it is expected that products are returned to providers, who assess their fitness for use.

In summary, depending on the reuse model, supply chains will need multiple transformations, which are likely to require significant investments from all stakeholders (e.g., businesses, governments) and will determine the transition of the industry to a reuse economy system. After selecting one of the two reuse models, businesses have to carefully consider the implications of any increased complexity brought by the model and if they can technically and financially afford the required infrastructural and managerial investments.

\subsection{Enhancing Reuse through Multi-Model Offerings}

The reuse framework developed in this research presents foundational models. Some providers offer consumers multi-mode options. This illustrates that there is scope for businesses to provide consumers with alternative pathways to reuse, thereby enhancing the adoption of reuse by the industry. In particular, by giving the option to reuse either in the exclusive or sequential mode within the same offering, the prospect of reusing products can be made appealing to different groups of consumers. In addition, systems with multimodel options can increase the potential for product reuse in circumstantial purchases, such as when the consumer arrives at the location of purchase unprepared (i.e., without bringing their reusable vessel for refill) but wants to purchase consumables from within the offering by borrowing a vessel for refill.

Some providers adopt multi-model combinations that require consumers to reuse several products simultaneously (e.g., reusable products and assistive products). This illustrates that there is scope for businesses to extend the reusability of their offerings to include several elements, enhancing the longevity of products and ultimately increasing their environmental value. In addition, the use of multi-model combinations can be extended beyond durable FMCGs to include assistive appliances. For example, sequential reuse can be adopted to lease assistive appliances to consumers, and their recovery for reuse can be supported by refurbishment services (e.g., coffee machine rental (e.g., Bundless [105]). 


\subsection{Limitations and Further Research}

The reuse models that emerged in this research have been configured based on existing cases of reuse offerings. In general, reuse models are still in the early stages of adoption within FMCG markets with scope for business innovation, which could lead to the development of novel models. Ultimately, any advancement of reuse would call for an extension of the five reuse models framework.

The methodology used to categorise the reuse models identified key reuse system elements at a macro level (i.e., reuser behaviour, reusable product, and reuse-enabling infrastructure for preparation and recovery). Whilst this research provides an insight into the types of access that the consumer has to infrastructure, the framework does not characterise this aspect. Its future consideration has the potential to influence the sustainability and adoption of reuse models. In addition, whilst the sample used in this study included offerings that operate across various markets worldwide, future research could investigate how the identified reuse models function within specific geographical regions. The methodology used to assess the capability of each model to deliver environmental value included a list of EVP factors and their realisation methods. This list is limited to three core environmental themes focused on assessing resource efficiency, recyclability, and reusability. Whilst these three themes allow for an early-stage qualitative assessment, there is scope for extension to include other pillars of sustainability, such as social and economic aspects.

Further research could include investigation of exclusive and sequential reuse behaviour chains to broaden the understanding of consumer participation in those systems. This could include the identification of psychological and systemic barriers and drivers to the adoption of reuse in the two behavioural modes. As highlighted by the evaluation of the EVP factors, further research should include investigation of the recyclability of reusable products. This could include the identification of materials suitable for both reuse and recycling. In addition, as the reuse models framework centres on the reuse of FMCGs, further research could focus on the reuse of infrastructure. This could advance the framework by adding further levels of distinction between the models, thereby providing an extended view of multi-model approaches. Finally, as the data sample includes reuse offerings from "traditional" FMCG categories, there is potential to extend the framework to include fast-consumed products from other industries, such as fashion or electronics.

\section{Conclusions}

In the FMCG industry, improving the efficiency of material resources has become a key issue. One route to achieve this is to increase the recycling of packaging and products. However, recycling alone does not address the problem of material intensity, which is typical of the industry. In order to reduce the flow of materials needed to satisfy consumers needs, a growing number of businesses are starting to move beyond recycling by implementing novel reuse models and consumption systems, such as refill stations. However, the literature on reuse models is scarce and does not provide a comprehensive view on the key dimensions of reuse, limiting the industry's ability to implement reuse successfully.

This research has carried out a comprehensive analysis of reuse offerings in the FMCG industry showing that reusable products are predominantly durable packaging for beverage, food and personal and home care goods. For the first time, this analysis has led to the characterisation of reuse models based on the behaviours expected by consumers, the ownership of products, and the interaction between products and infrastructure. The resulting models provide a holistic view on reuse that goes beyond current frameworks based on users' actions such as refill and return [25]. Specifically, this research has characterised the architectural components of reuse models that have a central role in facilitating reuse, including the reuser behaviour, the reusable product, and reuse-enabling infrastructure. As a result, five main reuse models were identified and presented in a framework. Three models involve exclusive reuse, where the reuser consumes individually and keeps the reusable 
product, while two models involve sequential reuse, where the reuser consumes along with multiple successive individuals and returns the reusable product.

This research also carried out a qualitative assessment of the environmental value potential of the reuse models to ascertain their capability to deliver a "true" circular economy for resources. This has shown that reuse models are often ineffective at closing the loops of material flows due to limitations to the recycling of reusable products. Ultimately, improvements need to be made to the design of reusable products by ensuring that the material content is recycled and fully recyclable where possible. Nonetheless, the reuse models presented have a greater potential to deliver environmental value than the current linear model. Factors such as reducing the input and use of natural resources and retaining the value of products, components, and materials in the economy make this possible. When compared to exclusive reuse models, sequential reuse models were found to have a greater capability to make the journey of resources continue towards recycling due to infrastructural elements that enable the closure of material loops. The success of reuse models is equally dependent on consumer behaviour compliance and the deployment of adequate infrastructure by providers.

The reuse models framework proposed in this research can guide a business willing to pursue reuse to understand how to modify current linear practices and develop novel circular propositions. Specifically, the models can help a business identify if a reuse offering fits with their consumers' needs and their own technical, infrastructural, and financial capabilities. In addition, the methodology adopted in this research to assess the environmental value proposition of reuse models can be used by a business to evaluate the circularity of future reuse offerings at the early stages of development.

Author Contributions: The authors contributions are as follows: Conceptualisation, Ż.M., M.A., A.Z. and C.T.; Methodology, Ż.M. and M.A.; Validation, Ż.M., M.A. and A.Z.; Formal Analysis, Ż.M. and M.A.; Investigation, Ż.M. and M.A.; Data Curation, Ż.M.; Writing-Original Draft Preparation, Ż.M., M.A. and C.T.; Writing—Review and Editing, Ż.M., M.A., C.T. and A.Z.; Visualisation, Ż.M.; Funding Acquisition, M.A. All authors have read and agreed to the published version of the manuscript.

Funding: This research was funded by the UK Engineering and Physical Sciences Research Council (EPSRC) through the Plastic and Research Innovation Fund (PRIF) and grant EP/S025456/1 titled Holistic Integration of technology, design and policy for a greener plastic future.

Institutional Review Board Statement: Not applicable.

Informed Consent Statement: Not applicable.

Data Availability Statement: The data presented in this study are available on request from the corresponding author.

Conflicts of Interest: The authors declare no conflict of interest. 


\section{Appendix A}

\begin{tabular}{|c|c|c|c|c|}
\hline reuse model & $\mathbf{V}^{* *}$ & reuse offering & FMCG category & References \\
\hline $\begin{array}{l}\text { Model } 1 \\
\text { Exclusively reused } \\
\text { products }\end{array}$ & & $\begin{array}{l}\wedge \text { Bare and Boho } \\
\text { ^Bloom and Nora } \\
\text { *BBillie Wonder } \\
\text { Cheeky Wipes } \\
\text { Circular and Co Cup } \\
\text { Dopper bottle } \\
\text { ^Eco Vibe (reusable make-up removal pads) } \\
\text { ^FaceHalo } \\
\text { Kalika Beeswax Wrap } \\
\text { ^Lunette } \\
\text { Onya (tote bag) } \\
\text { Stojo } \\
\text { ^Tabitha Eve (nail polish removal pads) } \\
\text { Way Cup } \\
\text { ^Zero Cup }\end{array}$ & $\begin{array}{l}\text { baby care } \\
\text { personal care } \\
\text { baby care } \\
\text { baby care, personal care } \\
\text { beverages } \\
\text { beverages } \\
\text { personal care } \\
\text { personal care } \\
\text { food } \\
\text { personal care } \\
\text { transit packaging } \\
\text { beverages } \\
\text { personal care } \\
\text { beverages } \\
\text { personal care }\end{array}$ & 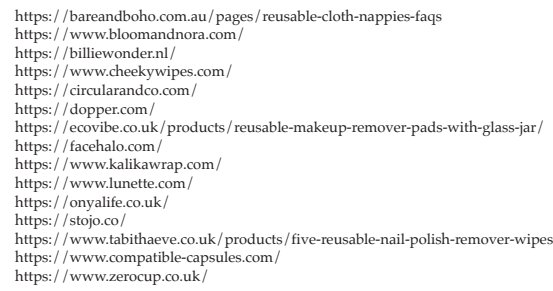 \\
\hline $\begin{array}{l}\text { Model } 2 \\
\text { Exclusively reused } \\
\text { products with } \\
\text { reuse-enabling } \\
\text { infrastructure }\end{array}$ & & $\begin{array}{l}\text { Algramo Tricycle } \\
\text { Algramo (in-store dispenser) } \\
\text { *Billie Wonder (nappies) } \\
\text { Blueland } \\
\text { ^Champion Shave } \\
\text { *Cif Eco Refill } \\
\text { Cleanyst } \\
\text { *Dazz } \\
\text { Drinkfinity } \\
\text { Ecover Refill } \\
\text { *Fill Refill } \\
\text { Gatorade (pod and bottle) } \\
\text { ^Gruum Razor } \\
\text { Humankind Deodorant Refill } \\
\text { "Koin the Pipe } \\
\text { Kjaer Weiss Refills } \\
\text { Miwa } \\
\text { Myro Deodorant Refill } \\
\text { *Ocean Saver Eco Drops } \\
\text { Olay Whip Refill Pods } \\
\text { Pepsi Home-Made } \\
\text { Replenish } \\
\text { "SodaStream } \\
\text { Splosh } \\
\text { ^Up Circle Safety Razor } \\
\text { *Waitrose and Partners Unpacked } \\
\text { ^Wearth Modular Toothbrush }\end{array}$ & $\begin{array}{l}\text { home care } \\
\text { food care } \\
\text { baby care } \\
\text { home care } \\
\text { personal care } \\
\text { home care } \\
\text { home care, personal care } \\
\text { home care } \\
\text { beverages } \\
\text { home care } \\
\text { personal care, home care } \\
\text { beverages } \\
\text { personal care } \\
\text { personal care } \\
\text { beverages } \\
\text { personal care } \\
\text { food } \\
\text { personal care } \\
\text { home care } \\
\text { personal care } \\
\text { beverages } \\
\text { home care } \\
\text { beverages } \\
\text { home care } \\
\text { personal care } \\
\text { food, beverages } \\
\text { personal care }\end{array}$ & 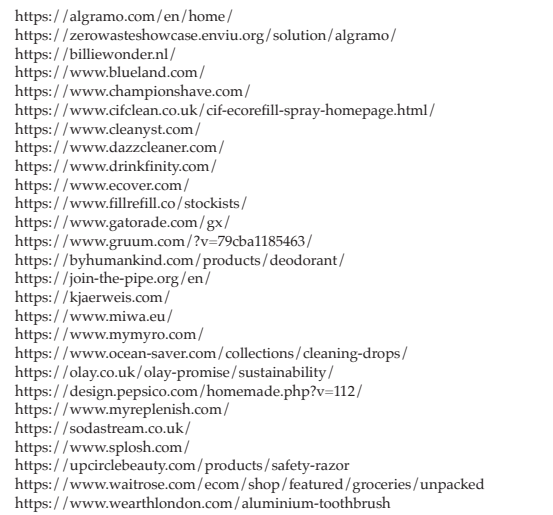 \\
\hline $\begin{array}{l}\text { Model } 3 \\
\text { Reuse-enabling } \\
\text { infrastructure for } \\
\text { exclusively reused } \\
\text { products }\end{array}$ & & 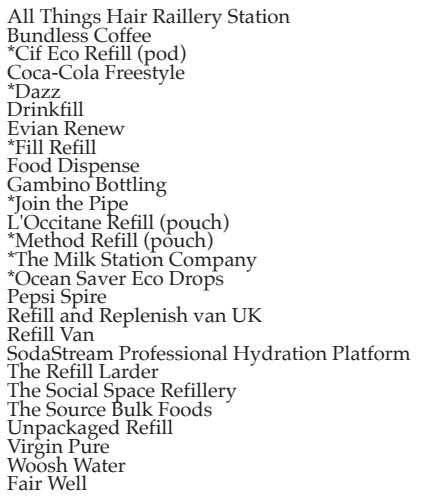 & $\begin{array}{l}\text { personal care } \\
\text { beverages } \\
\text { home care } \\
\text { beverages } \\
\text { home care } \\
\text { beverages } \\
\text { beverages } \\
\text { personal care, home care } \\
\text { food } \\
\text { beverages } \\
\text { beverages } \\
\text { personal care } \\
\text { personal care, home care } \\
\text { food } \\
\text { home care } \\
\text { beverages } \\
\text { food, beverages } \\
\text { food, beverages } \\
\text { beverages } \\
\text { food } \\
\text { food } \\
\text { food } \\
\text { food } \\
\text { beverages } \\
\text { beverages } \\
\text { food, home care }\end{array}$ & 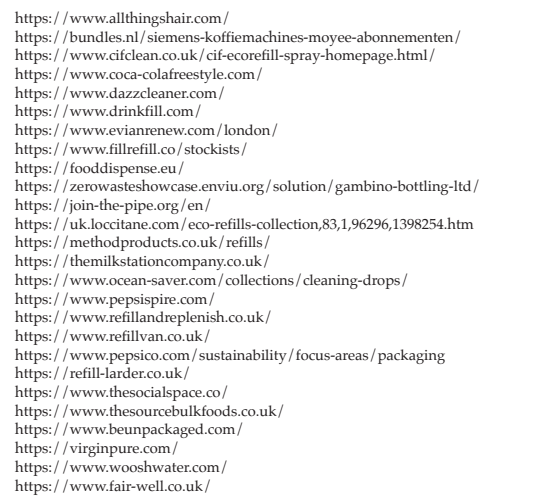 \\
\hline $\begin{array}{l}\text { Model } 4 \\
\text { Sequentially reused } \\
\text { products with } \\
\text { reuse-enabling } \\
\text { infrastructure }\end{array}$ & & $\begin{array}{l}\text { Cozie Refill } \\
\text { Jean Bouteille } \\
\text { *The Milk Station Company } \\
{ }^{*} \text { Waitrose and Partners Unpacked }\end{array}$ & $\begin{array}{l}\text { personal care } \\
\text { food, beverages, home care } \\
\text { food } \\
\text { food, beverages }\end{array}$ & $\begin{array}{l}\text { https://www.cozie-bio.com/ } \\
\text { https://www.jeanbouteille.fr/ } \\
\text { https://themilkstationcompany.co.uk/ } \\
\text { https://www.waitrose.com//ecom/shop/featured/groceries/unpacked/ }\end{array}$ \\
\hline $\begin{array}{l}\text { Model } 5 \\
\text { Sequentially reused } \\
\text { products }\end{array}$ & $\begin{array}{l}\text { b } \\
\text { b } \\
\text { b } \\
\text { b } \\
\text { c } \\
\text { b } \\
\text { b } \\
\text { b } \\
\text { b } \\
\text { b } \\
\text { b } \\
\text { b } \\
\text { b } \\
\text { b } \\
\text { d } \\
\text { d } \\
\text { b } \\
\text { b } \\
\text { b } \\
\text { b } \\
\text { b } \\
\text { b } \\
\text { d } \\
\text { b } \\
\text { c } \\
\text { b } \\
\text { b } \\
\text { b } \\
\text { a }\end{array}$ & $\begin{array}{l}\text { Coca-Cola Brazil (bottle reuse scheme) } \\
\text { Cup Club } \\
\text { CupKita } \\
\text { Dabba Drop } \\
\text { Danone Water Jugs } \\
\text { Dirty Hippie cosmetics } \\
\text { Econesia } \\
\text { Enviro Cup } \\
\text { Freshbowl } \\
\text { Go Box } \\
\text { Hepi Circle } \\
\text { Infinity Goods } \\
\text { Keko Box } \\
\text { Koiismetics } \\
\text { Lindström's Returnable Bag } \\
\text { Liviri } \\
\text { Loop (packaging and transit tote (*d)) } \\
\text { Milk and More } \\
\text { Muuse } \\
\text { Plaine Products } \\
\text { ReCircle } \\
\text { ReCup } \\
\text { RePack } \\
\text { Returnr with Deliveroo } \\
\text { *SodaStream } \\
\text { Starbucks UK Gatwick Airport (cup reuse trial) } \\
\text { The Wally Shop } \\
\text { Vessel Works } \\
\text { ^Washcot (nappies and transit packaging (*d)) }\end{array}$ & $\begin{array}{l}\text { beverages } \\
\text { beverages } \\
\text { beverages } \\
\text { food } \\
\text { beverages } \\
\text { personal care } \\
\text { beverages } \\
\text { beverages } \\
\text { food } \\
\text { food } \\
\text { home care } \\
\text { food, beverages } \\
\text { food } \\
\text { personal care } \\
\text { transit packaging } \\
\text { transit packaging } \\
\text { food, beverages, personal care } \\
\text { food } \\
\text { food, beverages } \\
\text { personal care } \\
\text { food } \\
\text { beverages } \\
\text { transit packaging } \\
\text { food } \\
\text { beverages } \\
\text { beverages } \\
\text { food } \\
\text { beverages } \\
\text { baby care }\end{array}$ & 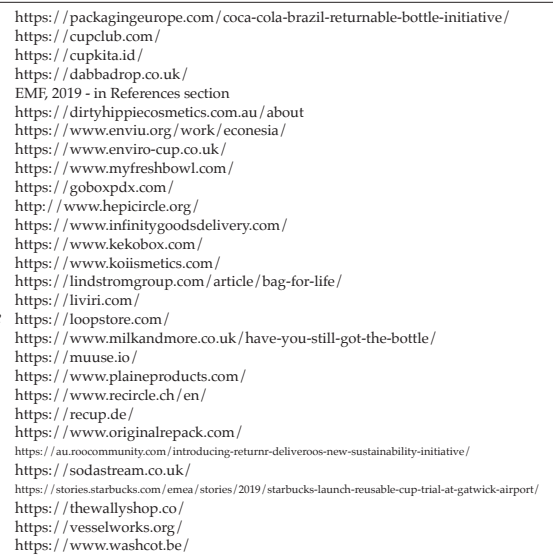 \\
\hline
\end{tabular}

Figure A1. Sample cases. 


\section{Appendix B}

Provider-owned are reusable products returned to the provider following consumption; the mechanism that ensures that the provider retains ownership of these products can vary from "hard", where the consumer has a legal obligation (e.g., terms of use, or contract) to return borrowed products to "soft", where the consumer is incentivised to return borrowed products but has flexibility to retain them.

\section{Appendix C}

The consumption phase typically falls after the production phase and commences from the point in which a product is available on the market. The end of the consumption phase marks the end of a single life cycle of a product, after which the product flows either out of the system into the waste-stream or into its next life cycle (as a product or a material).

\section{Appendix D}

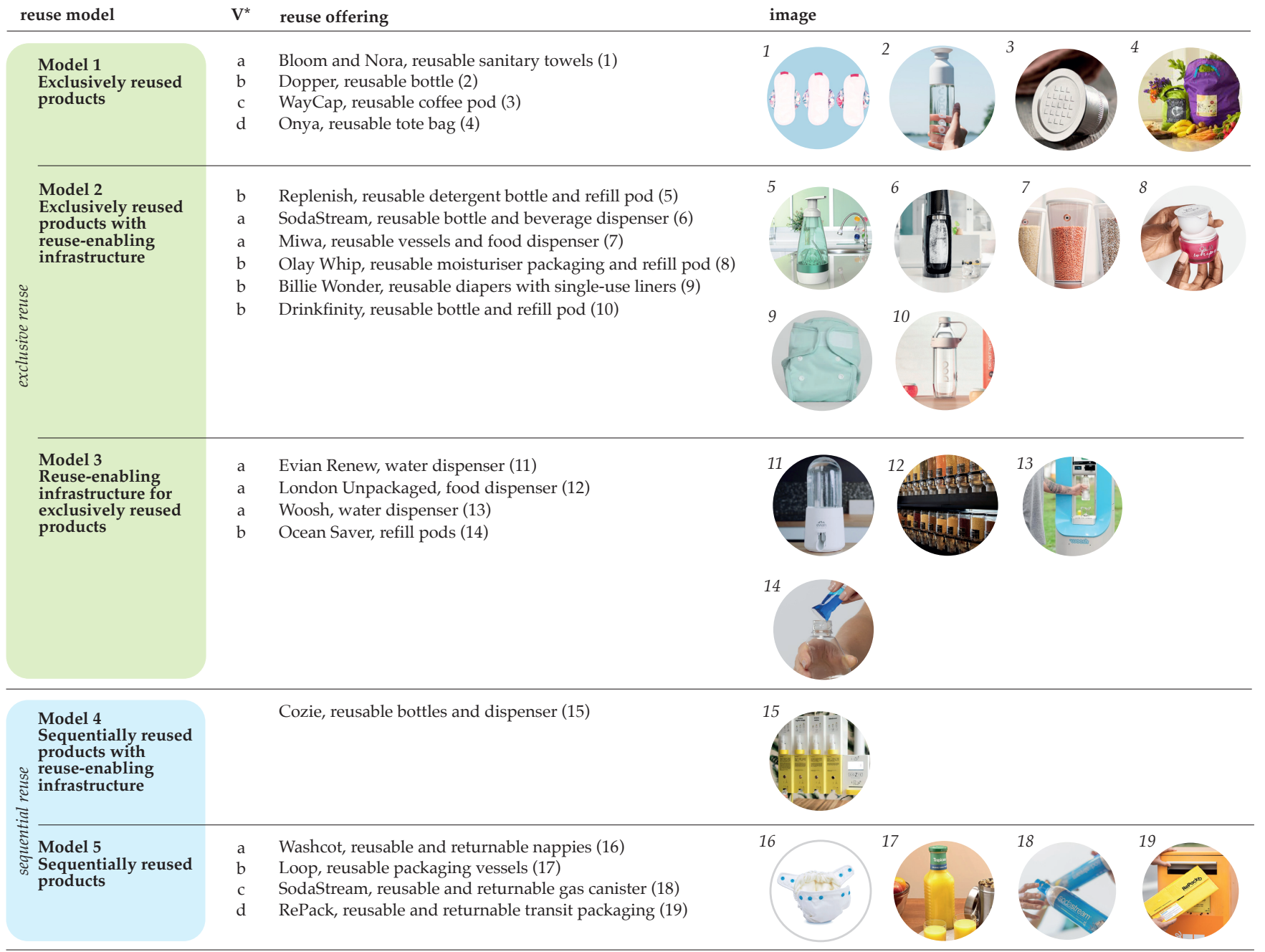

${ }^{*}$ Model variant

Note: references to offerings can be located in Figure A1, Appendix A. Image credits: providers' websites.

Figure A2. Reuse models: offering examples.

\section{Appendix E}

Exclusive reuse is a behavioural mode for ownership as much as for consumption by leasing, whereby products are accessed by a single consumer and remain in their possession for an agreed period of time or number of uses, after which they are returned 
to the provider. Although leasing is more common in industries such as automotive and aviation, it is possible that novel variants of exclusive reuse involving product or packaging leasing will emerge in the FMCG sector. In these variants, the consumer is provided with an option to reuse whilst the product or packaging remains in the property of the business. An example for the FMCG sector is exclusively reused nappies offered in leasing [106].

\section{References}

1. Zeeuw van der Laan, A.; Aurisicchio, M. Archetypical consumer roles in closing the loops of resource flows for Fast-Moving Consumer Goods. J. Clean. Prod. 2019, 236, 117475. [CrossRef]

2. Lacy, P.; Long, J.; Spindler, W. Fast-Moving Consumer Goods (FMCG) Industry Profile. In The Circular Economy Handbook; Palgrave Macmillan: London, UK, 2020.

3. Ellen MacArthur Foundation. Towards a Circular Economy Vol.3: Accelerating the Scale-Up across Global Supply Chains; Ellen MacArthur Foundation: Cowes, UK, 2014.

4. Ellen MacArthur Foundation. Towards the Circular Economy Vol. 2: Opportunities for the Consumer Goods Sector; Ellen MacArthur Foundation: Cowes, UK, 2013.

5. WRAP. Design Tips for Making Rigid Plastic Packaging More Recyclable; V1 18/10/2018; Waste and Resources Action Programme: Banbury, UK, 2018.

6. Ellen MacArthur Foundation. The New Plastics Economy Rethinking the Future of Plastics; Ellen MacArthur Foundation: Cowes, UK, 2016.

7. Johansson, K. Understanding Recycling Behavior-A Study of Motivational Factors behind Waste Recycling. In Proceedings of the 8th International Conference on Waste Management and the Environment, Valéncia, Spain, 7-9 June 2016; Wessex Institute of Technology Press: Ashurst, UK, 2016.

8. Hahladakis, J.; Iacovidou, E. An overview of the challenges and trade-offs in closing the loop of post-consumer plastic waste (PCPW): Focus on recycling. J. Hazard. Mater. 2019, 380, 120887. [CrossRef]

9. Cooper, T. Beyond Recycling: The Longer Life Option; New Economics Foundation: London, UK, 1994.

10. Coelho, P.M.; Corona, B.; ten Klooster, R.; Worrell, E. Sustainability of reusable packaging-Current situation and trends. Resour. Conserv. Recycl. X 2020, 6, 100037. [CrossRef]

11. British Standards Institution. BS EN 13429: 2004. Packaging Reuse. Available online: https://shop.bsigroup.com/ProductDetail? pid $=000000000030094797$ (accessed on 12 October 2020).

12. European Commission. Directive 2008/98/EC of the European Parliament and of the Council of 19 November 2008 on Waste and Repealing Certain Directives. 2008. Available online: http:/ / data.europa.eu/eli/dir/2008/98/oj (accessed on 12 October 2020).

13. European Commission. Directive 2009/125/EC of the European Parliament and of the Council of 21 October 2009 Establishing a Framework for the Setting of Ecodesign Requirements for Energy-Related Products. 2009. Available online: http://data.europa. eu/eli/dir/2009/125/oj (accessed on 12 October 2020).

14. Kunamaneni, S.; Jassi, S.; Hoang, D. Promoting reuse behaviour: Challenges and strategies for repeat purchase, low-involvement products. Sustain. Prod. Consum. 2019, 20, 253-272. [CrossRef]

15. Mahmoudi, M.; Parviziomran, I. Reusable packaging in supply chains: A review of environmental and economic impacts, logistics system designs, and operations management. Int. J. Prod. Econ. 2020, 228, 107730. [CrossRef]

16. International Organization for Standardization. ISO 18603: 2013. Packaging and the Environment-Reuse. Available online: https: / / shop.bsigroup.com/ProductDetail/?pid=000000000030240157 (accessed on 12 October 2020).

17. Nodarou, E.; Frederick, C.; Hein, A. Another (mud) brick in the wall: Scientific analysis of Bronze Age earthen construction materials from three sites in East Crete. J. Archaeol. Sci. 2008, 35, 2997-3015. [CrossRef]

18. Kavanagh, R. A Reconsideration of Razors in the Irish Earlier Bronze Age. J. R. Soc. Antiqu. Irel. 1991, 121, 77-104.

19. Damme, I.; Vermoesen, R. Second-hand consumption as a way of life: Public auctions in the surroundings of Alost in the late eighteenth century. Contin. Chang. 2009, 24, 275-305. [CrossRef]

20. License, T. Normalising Bottle Reuse. Lessons from the Victorians on the Limits of Voluntary Schemes. Hist. Policy 2020. Available online: http:/ / www.historyandpolicy.org/policy-papers/papers/normalising-bottle-return-and-reuse-lessons-fromthe-victorians-on-the-limits-of-voluntary-schemes (accessed on 12 October 2020).

21. Clark, G. The milkman stays alive. Eur. Dairy Mag. 1990, 3, 51-52.

22. Strasser, S. Waste and Want: A Social History of Trash; Henry Holt and Company: New York, NY, USA, 2014 ; ISBN 1466872284.

23. British Standards Institution. BS 8001: 2017. Framework for Implementing the Principles of the CE in Organisations. Available online: https: / / shop.bsigroup.com/ProductDetail?pid=000000000030334443 (accessed on 12 October 2020).

24. Lofthouse, V.; Bhamra, T.; Trimingham, R. Investigating customer perceptions of refillable packaging and assessing business drivers and barriers to their use. Packag. Technol. Sci. 2009, 22, 335-348. [CrossRef]

25. Ellen MacArthur Foundation. Reuse—Rethinking Packaging; Ellen MacArthur Foundation: Cowes, UK, 2019.

26. Mansour, N.; Ceschin, F.; Harrison, D.; Long, Y. Mapping and classifying business models to replace single-use packaging in the food and beverage industry: A strategic design tool. Learn. Netw. Sustain. 2019, 6, 418-422. 
27. Long, Y.; Ceschin, F.; Mansour, N.; Harrison, D. Product-Service Systems applied to reusable packaging systems: A strategic design tool. In Proceedings of the 22nd dmi: Academic Design Management Conference Proceedings-Impact the Future by Design, Virtual: Design Management Institute, Toronto, ON, Canada, 5-6 August 2020; pp. 539-553.

28. Tassell, C.; Aurisicchio, M. The Evolution of Reuse and Recycling Behaviours: An Integrative Review with Application to the Fast-Moving Consumer Goods Industry. In Proceedings of the IS4CE2020 Conference of the International Society for the Circular Economy, Exeter, UK, 6-7 July 2020; University of Exeter: Exeter, UK, 2020.

29. Lofthouse, V.; Trimingham, R.; Bhamra, T. Reinventing refills: Guidelines for design. Packag. Technol. Sci. 2017, 30, 809-818. [CrossRef]

30. Choate, B.; Davis, B.Y.; Verrecchia, J. Campus bottled water bans, not always the solution. Int. J. Sustain. High. Educ. 2018, 19, 987-997. [CrossRef]

31. Ertz, M.; Huang, R.; Jo, M.; Karakas, F.; Sarigöllü, E. From single-use to multi-use: Study of consumers' behavior toward consumption of reusable containers. J. Environ. Manag. 2017, 193, 334-344. [CrossRef] [PubMed]

32. Vaughan, P.; Cook, M.; Trawick, P. A Sociology of Reuse: Deconstructing the Milk Bottle. Sociol. Rural. 2007, 47, 120-134. [CrossRef]

33. Bashir, H.; Jørgensen, S.; Pedersen, L.; Skard, S. Experimenting with sustainable business models in fast moving consumer goods. J. Clean. Prod. 2020, 270, 122302. [CrossRef]

34. Miller, J.; Bennett, C.; Cumming, G. Potentially changing health behaviour using nappy 'nudges'. Br. J. Midwifery 2011, 19, 246-251. [CrossRef]

35. Poortinga, W.; Whitaker, L. Promoting the Use of Reusable Coffee Cups through Environmental Messaging, the Provision of Alternatives and Financial Incentives. Sustainability 2018, 10, 873. [CrossRef]

36. Rosa, P.; Sassanelli, C.; Terzi, S. Circular Business Models versus circular benefits: An assessment in the waste from Electrical and Electronic Equipments sector. J. Clean. Prod. 2019, 231, 940-952. [CrossRef]

37. Manninen, K.; Koskela, S.; Antikainen, R.; Bocken, N.; Dahlbo, H.; Aminoff, A. Do circular economy business models capture intended environmental value propositions? J. Clean. Prod. 2018, 171, 413-422. [CrossRef]

38. Changwichan, K.; Gheewala, S. Choice of materials for takeaway beverage cups towards a circular economy. Sustain. Prod. Consum. 2020, 22, 34-44. [CrossRef]

39. Hoffmann, B.S.; Morais, J.D.; Teodoro, P.F. Life cycle assessment of innovative circular business models for modern cloth diapers. J. Clean. Prod. 2020, 249, 119364. [CrossRef]

40. Hait, A.; Powers, S. The value of reusable feminine hygiene products evaluated by comparative environmental life cycle assessment. Resour. Conserv. Recycl. 2019, 150, 104422. [CrossRef]

41. Makov, T.; Meylan, G.; Powell, J.T.; Shepon, A. Better than bottled water?-Energy and climate change impacts of on-the-go drinking water stations. Resour. Conserv. Recycl. 2019, 143, 320-328. [CrossRef]

42. Stajcer, D.; ten Houten, M.R.; Wiegersma, S.; Kok, I.C.; Alfers, A.L.E. LCA Voor Meermalige en Eenmalige Verpakkingssystemen Met Statiegeld Voor Frisdranken en Waters; TNO: Delft, The Netherlands, 2001.

43. Landi, D.; Germani, M.; Marconi, M. Analyzing the environmental sustainability of glass bottles reuse in an Italian wine consortium. Procedia CIRP 2019, 80, 399-404. [CrossRef]

44. Kuzmina, K.; Prendeville, S.; Walker, D.; Charnley, F. Future scenarios for fast-moving consumer goods in a circular economy. Futures 2019, 107, 74-88. [CrossRef]

45. Zero Waste Living Lab. Zero Waste Living Lab Map. 2019. Available online: https:/ / zerowasteshowcase.enviu.org (accessed on 15 March 2019).

46. Tukker, A. Eight types of product-service system: Eight ways to sustainability? Experiences from SusProNet. Bus. Strategy Environ. 2004, 13, 246-260. [CrossRef]

47. Wieser, H. Consumption Work in the Circular and Sharing Economy: A Literature Review. 2019. Available online: https: //www.sci.manchester.ac.uk/research/projects/consumption-work/ (accessed on 10 December 2020).

48. European Environment Agency. Circular Economy in Europe. Developing the Knowledge Base; EEA Report No 2/2016; European Environment Agency: København, Denmark, 2016.

49. Van den Berg, M.R.; Bakker, C.A. A product design framework for a circular economy. In PLATE Product Lifetimes and the Environment; Nottingham University of Technology: Nottingham, UK, 2015.

50. Bocken, N.; de Pauw, I.; Bakker, C.; van der Grinten, B. Product design and business model strategies for a circular economy. J. Ind. Prod. Eng. 2016, 33, 308-320. [CrossRef]

51. Ellen MacArthur Foundation. Cities and Circular Economy of Food; Ellen MacArthur Foundation: Cowes, UK, 2019.

52. Palmer, A.; Mortimer, P.; Greening, P.; Piecyk, M.; Dadchih, P. A cost and $\mathrm{CO}_{2}$ comparison of using trains and higher capacity trucks when UK FMCG companies collaborate. Transp. Res. Part D Transp. Environ. 2018, 58, 94-107. [CrossRef]

53. De Aguiar, J.; de Oliveira, L.; da Silva, J.; Bond, D.; Scalice, R.; Becker, D. A design tool to diagnose product recyclability during product design phase. J. Clean. Prod. 2017, 141, 219-229. [CrossRef]

54. Carey, J. News Feature: On the brink of a recycling revolution? Proc. Natl. Acad. Sci. USA 2017, 114, 612-616. [CrossRef]

55. Wastling, T.; Charnley, F.; Moreno, M. Design for Circular Behaviour: Considering Users in a Circular Economy. Sustainability 2018, 10, 1743. [CrossRef] 
56. Eriksen, M.; Damgaard, A.; Boldrin, A.; Astrup, T. Quality Assessment and Circularity Potential of Recovery Systems for Household Plastic Waste. J. Ind. Ecol. 2018, 23, 156-168. [CrossRef]

57. Mont, O. Innovative approaches to optimising design and use of durable consumer goods. Int. J. Prod. Dev. 2008, 6, 227-250. [CrossRef]

58. Den Hollander, M.; Bakker, C.; Hultink, E. Product Design in a Circular Economy: Development of a Typology of Key Concepts and Terms. J. Ind. Ecol. 2017, 21, 517-525. [CrossRef]

59. Mugge, R.; Schoormans, J.P.L.; Schifferstein, H.N.J. Design Strategies to Postpone Consumers' Product Replacement: The Value of a Strong Person-Product Relationship. Des. J. 2005, 8, 38-48. [CrossRef]

60. Jensen, J.; Remmen, A. Enabling Circular Economy Through Product Stewardship. Procedia Manuf. 2017, 8, 377-384. [CrossRef]

61. Grace, R. In the Crosshairs: Single-Use, Disposable Packaging. Plast. Eng. 2019, 75, 18-23. [CrossRef]

62. Smithers, R. Waitrose Launches Packaging-Free Trial. The Guardian. 4 June 2019. Available online: https:/ / www.theguardian. com/business/2019/jun/04/waitrose-launches-packaging-free-trial (accessed on 23 September 2019).

63. FaceHalo. Sustainability. Changing the Way the World Removes Makeup. 2020. Available online: https://facehalo.com/pages/ sustainability (accessed on 12 October 2020).

64. Accorsi, R.; Baruffaldi, G.; Manzini, R. A closed-loop packaging network design model to foster infinitely reusable and recyclable containers in food industry. Sustain. Prod. Consum. 2020, 24, 48-61. [CrossRef]

65. Govindan, K. Sustainable consumption and production in the food supply chain: A conceptual framework. Int. J. Prod. Econ. 2018, 195, 419-431. [CrossRef]

66. Newby, L. Sustainable local economic development: A new agenda for action? Local Environ. 1999, 4, 67-72. [CrossRef]

67. Vessel Works. How It Works. Frequently Asked Questions. 2020. Available online: https://vesselworks.org/faq (accessed on 12 October 2020).

68. Unilever. Cif Ecorefill Bathroom Spray. 2020. Available online: https://www.cifclean.co.uk/products/catalog/cif-ecorefillpower-\&-shine-bathroom-cleaner-spray-70ml.html (accessed on 12 October 2020).

69. SodaStream. Bubbles 101: All You Need to Know about Gas Cylinders. 2020. Available online: https://sodastream.co.uk/blogs/ explore/bubbles-101-all-you-need-to-know-about-gas-cylinders (accessed on 12 October 2020).

70. Geueke, B.; Groh, K.; Muncke, J. Food packaging in the circular economy: Overview of chemical safety aspects for commonly used materials. J. Clean. Prod. 2018, 193, 491-505. [CrossRef]

71. British Glass. Maximising the Recyclability of Glass Packaging. Sheffield, UK. 2019. Available online: https://www.britglass.org. uk/sites/default/files/00017-E2-19_Maximising_the_recyclability_of_glass_packaging_WEB.pdf (accessed on 12 October 2020).

72. Dopper. Why Isn't the Dopper Made of Recycled Plastic? 2019. Available online: https://help.dopper.com/hc/en-us/articles/11 5005755349-Why-isn-t-the-Dopper-made-of-recycled-plastic- (accessed on 12 October 2020).

73. Zeeuw van der Laan, A.; Aurisicchio, M. A framework to use product-service systems as plans to produce closed-loop resource flows. J. Clean. Prod. 2020, 252, 119733. [CrossRef]

74. Ali, M.; Courtenay, P. Evaluating the progress of the UK's Material Recycling Facilities: A mini review. Waste Manag. Res. 2014, 32, 1149-1157. [CrossRef] [PubMed]

75. Zeeuw van der Laan, A.; Aurisicchio, M. Gateways to Revalorisation in Future Circular Cities: A Vision for Closed-Loop Resource Flows. In Proceedings of the Sustainable Innovation. 22nd International Conference. Road to 2030: Sustainability, Business Models, Innovation and Design, Epsom, UK, 4-5 March 2019; pp. 113-119.

76. Radhakrishnan, S. Environmental implications of reuse and recycling of packaging. In Environmental Footprints of Packaging; Springer: Berlin, Germany, 2015; Chapter 7; pp. 165-192.

77. Baxter, W.; Aurisicchio, M.; Childs, P. A psychological ownership approach to designing object attachment. J. Eng. Des. 2015, 26, 140-156. [CrossRef]

78. HM Revenue and Customs. Plastic Packaging Tax. 2020. Available online: https://www.gov.uk/government/publications/ introduction-of-plastic-packaging-tax/plastic-packaging-tax (accessed on 12 October 2020).

79. HM Government. Our Waste, Our Resources: A Strategy for England. 2018. Available online: https://assets.publishing.service. gov.uk/government/uploads/system/uploads/attachment_data/file/765914/resources-waste-strategy-dec-2018.pdf (accessed on 12 October 2020).

80. European Commission. Communication from The Commission to The European Parliament, The Council, The European Economic and Social Committee and The Committee of The Regions. Closing the Loop-An EU Action Plan for the Circular Economy. 2015. Available online: https://eur-lex.europa.eu/legal-content/EN/TXT/?uri=CELEX:52015DC0614 (accessed on 12 October 2020).

81. European Commission. EU Circular Economy Action Plan. A New Circular Economy Action Plan for a Cleaner and More Competitive Europe. 2020. Available online: https:/ / ec.europa.eu/environment/circular-economy (accessed on 12 October 2020).

82. WRAP. A Roadmap to 2025-The UK Plastics Pact. 2018. Available online: https://www.wrap.org.uk/content/the-uk-plasticspact-roadmap-2025 (accessed on 12 October 2020).

83. Ellen MacArthur Foundation. CE100. Members. 2017. Available online: https://www.ellenmacarthurfoundation.org/our-story/ our-network/members (accessed on 12 October 2020).

84. Muranko, Ż.; Aurisicchio, M.; Baxter, W.; Childs, P. Behaviour chains in circular consumption systems: The reuse of FMCGs. In Proceedings of the IS4CE2020 Conference of the International Society for the Circular Economy, Exeter, UK, 6-7 July 2020; University of Exeter: Exeter, UK, 2020. 
85. Sæter, F.; Alvarado, I.O.; Pettersen, I.N. Reuse Principle for Primary Packaging Circularity in the Food System. In Proceedings of the DS 101: Proceedings of NordDesign 2020, Lyngby, Denmark, 12-14 August 2020; p. 12, ISBN 9781912254088.

86. Baxter, W.; Aurisicchio, M.; Childs, P. Contaminated Interaction: Another Barrier to Circular Material Flows. J. Ind. Ecol. 2017, 21, 507-516. [CrossRef]

87. Gallego-Schmid, A.; Mendoza, J.M.F.; Azapagic, A. Environmental impacts of takeaway food containers. J. Clean. Prod. 2019, 211, 417-427. [CrossRef]

88. Amienyo, D.; Gujba, H.; Stichnothe, H.; Azapagic, A. Life cycle environmental impacts of carbonated soft drinks. Int. J. Lifecycle Assess. 2013, 18, 77-92. [CrossRef]

89. Dopper. Cleaning Tips for Your Dopper. Prevention. 2020. Available online: https://dopper.com/blog/cleaning-tips-dopper/ (accessed on 12 October 2020).

90. Zeeuw van der Laan, A.; Aurisicchio, M. Designing Product-Service Systems to Close Resource Loops: Circular Design Guidelines. Procedia CIRP 2019, 80, 631-636. [CrossRef]

91. Zhou, G.; Gu, Y.; Wu, Y.; Gong, Y.; Mu, X.; Han, H.; Chang, T. A systematic review of the deposit-refund system for beverage packaging: Operating mode, key parameter and development trend. J. Clean. Prod. 2020, 251, 119660. [CrossRef]

92. El-Tawy, N.; Gallear, D. Exploring the Supply Chain Agility Attributes in Fast Moving Consumer Goods Industry: A Case Study in the Middle East. In Proceedings of the European 2012, Mediterranean and Middle Eastern Conference on Information Systems, EMCIS 2012, Munich, Germany, 7-8 June 2012; pp. 89-102.

93. Bhardwaj, V.; Fairhurst, A. Fast Fashion: Response to Changes in the Fashion Industry. Int. Rev. Retail Distrib. Consum. Res. 2010, 20, 165-173. [CrossRef]

94. Caro, F.; Martìnez-De-Albèniz, V. Fast Fashion: Business Model Overview and Research Opportunities. Int. Ser. Oper. Res. Manag. Sci. 2015, 223, 237-264.

95. Greenpeace. A Crisis of Convenience-The Corporations Behind the Plastic Pollution Pandemic. 2018. Available online: https:/ / www.greenpeace.org/international/publication/19007/a-crisis-of-convenience-the-corporations-behind-the-plasticspollution-pandemic/ (accessed on 12 October 2020).

96. Murakami, S.; Oguchi, M.; Tasaki, T.; Daigo, I.; Hashimoto, S. Lifespan of Commodities, Part I. J. Ind. Ecol. 2010, 14, 598-612. [CrossRef]

97. Mont, O. Clarifying the concept of Product-Service System. J. Clean. Prod. 2002, 10, 237-245. [CrossRef]

98. Bortolini, M.; Galizia, F.; Mora, C.; Botti, L.; Rosano, M. Bi-objective design of fresh food supply chain networks with reusable and disposable packaging containers. J. Clean. Prod. 2018, 184, 375-388. [CrossRef]

99. Lofthouse, V.; Bhamra, T. Investigation into the Drivers and Barriers Affecting Refillable Packaging. 2006. Available online: https:/ / repository.lboro.ac.uk/articles/online_resource/Investigation_into_the_drivers_and_barriers_affecting_refillable_ packaging/9340139 (accessed on 12 October 2020).

100. Accorsi, R.; Cascini, A.; Cholette, S.; Manzini, R.; Mora, C. Economic and environmental assessment of reusable plastic containers: A food catering supply chain case study. Int. J. Prod. Econ. 2014, 152, 88-101. [CrossRef]

101. Ellen MacArthur Foundation. Holy Grail. Ellen MacArthur Foundation. 2019. Available online: https://www. newplasticseconomy.org/projects / pioneer (accessed on 12 October 2020).

102. Hayashi, N.; Koyanaka, S.; Oki, T. Constructing an automatic object-recognition algorithm using labeling information for efficient recycling of WEEE. Waste Manag. 2019, 88, 337-346. [CrossRef] [PubMed]

103. Breen, L. Give me back my empties or else! A preliminary analysis of customer compliance in reverse logistics practices (UK). Manag. Res. News 2006, 29, 532-551. [CrossRef]

104. Cimpan, C.; Maul, A.; Wenzel, H.; Pretz, T. Techno-economic assessment of central sorting at material recovery facilities-The case of lightweight packaging waste. J. Clean. Prod. 2016, 112, 4387-4397. [CrossRef]

105. Bundless. Frequently Asked Questions. 2020. Available online: https://bundles.nl/en/siemens-coffee-machines-moyeesubscriptions / (accessed on 12 October 2020).

106. Darwin Cloth Nappies Nt. Easy \& Convenient. Full Time Premium Rent and Wash Service. 2021. Available online: https: / / darwinclothnappiesnt.com.au/nappy-services\#page82_button4 (accessed on 2 January 2021). 